\title{
An Essential Role for Frizzled5 in Neuronal Survival in the Parafascicular Nucleus of the Thalamus
}

\author{
Chunqiao Liu, ${ }^{1}$ Yanshu Wang, ${ }^{1,4}$ Philip M. Smallwood, ${ }^{1,4}$ and Jeremy Nathans ${ }^{1,2,3,4}$ \\ Departments of ${ }^{1}$ Molecular Biology and Genetics, ${ }^{2}$ Neuroscience, and ${ }^{3}$ Ophthalmology, and the ${ }^{4}$ Howard Hughes Medical Institute, Johns Hopkins \\ University School of Medicine, Baltimore, Maryland 21205
}

\begin{abstract}
Frizzled5 (Fz5), a putative Wnt receptor, is expressed in the retina, hypothalamus, and the parafascicular nucleus (PFN) of the thalamus. By constructing $F z 5$ alleles in which $\beta$-galactosidase replaces Fz 5 or in which Cre-mediated recombination replaces Fz5 with alkaline phosphatase, we observe that Fz5 is required continuously and in a cell autonomous manner for the survival of adult PFN neurons, but is not required for proliferation, migration, or axonal growth and targeting of developing PFN neurons. A motor phenotype associated with loss of Fz5 establishes a role for the PFN in sensorimotor coordination. Transcripts coding for Wnt9b, the likely Fz5 ligand in vivo, and $\beta$-catenin, a mediator of canonical Wnt signaling, are both downregulated in the $\mathrm{Fz}^{-/-} \mathrm{PFN}$, implying a positive feedback mechanism in which Wnt signaling is required to maintain the expression of Wnt signaling components. These data suggest that defects in WntFrizzled signaling could be the cause of neuronal loss in degenerative CNS diseases.
\end{abstract}

Key words: parafascicular nucleus; neuronal survival; Wnt; Frizzled; neuronal death; thalamus

\section{Introduction}

Wnts, Frizzleds (Fzs), and a variety of proteins that regulate or mediate Wnt and/or Frizzled signaling play central roles in many aspects of mammalian nervous system development. For example, Wnt-1 and Wnt-3a control proliferation and patterning of progenitors in the dorsal neural tube (Megason and McMahon, 2002; Muroyama et al., 2002), Wnt-3a and lymphoid-enhancing factor-1 (Lef-1) are required for the proliferation of progenitors in the hippocampus (Galceran et al., 2000; Lee et al., 2000), Fz3 and Celsr3 control neural tube closure and axonal growth and guidance in the spinal cord and forebrain (Wang et al., 2002, 2006; Lyuksyutova et al., 2003; Tissir et al., 2005), and Wnt7a modulates axonal remodeling and synaptogenesis in the cerebellum (Hall et al., 2000). In contrast, in the mature nervous system, the roles of Wnts and Frizzleds are still mostly unexplored. However, the observation in hippocampal neuron cultures that $\beta$-catenin modulates dendritic branching in response to membrane depolarization suggests a role for Wnt signaling in the context of adult CNS plasticity (Yu and Malenka, 2003).

For mature CNS neurons in long-lived species such as humans, one of the biggest challenges is simply remaining alive. Circumstantial evidence suggests that Wnt signaling may play a role in determining the balance between neuronal survival and death in a variety of degenerative disease states (De Ferrari and

\section{Received March 11, 2008; revised April 15, 2008; accepted April 20, 2008.}

We thank Dr. King-wai Yau for the use of the infrared light source and image-converting goggles; Tudor Badea, Michael Caterina, Xinzhong Dong, and Anthony Wynshaw-Boris for advice; Xin Ye for advice and materials; and Tudor Badea, Joseph Babcock, and Amir Rattner for helpful comments on this manuscript.

Correspondence should be addressed to Dr. Jeremy Nathans, Department of Molecular Biology and Genetics, Johns Hopkins University School of Medicine, 805 PCTB, 725 North Wolfe Street, Baltimore, MD 21205. E-mail: jnathans@jhmi.edu.

DOI:10.1523/JNEUROSCI.1056-08.2008

Copyright $\odot 2008$ Society for Neuroscience $\quad$ 0270-6474/08/285641-13\$15.00/0
Moon, 2006). For example, in humans, common haplotype variants in the LRP6 gene are associated with an increased risk for Alzheimer's disease (De Ferrari et al., 2007). In mice, Lucas et al. (2001) and Gomez-Sintes et al. (2007) used tetracyclineregulated transgene expression to show that acutely increasing or decreasing the activity of glycogen synthase kinase (GSK)-3 $\beta$, a key intermediary in canonical Wnt signaling, leads to neuronal death. Interestingly, increased GSK-3 $\beta$ leads to hyperphosphorylation of Tau protein and its aberrant subcellular localization, a hallmark of Alzheimer's disease neuropathology. Similarly, Carmichael et al. (2002) have shown that polyglutamine tract toxicity is reduced if GSK- $3 \beta$ activity is lowered either pharmacologically or genetically. At present, the only Wnt or Frizzled mutant reported to cause a neurodegeneration phenotype is the Fz4 knockout mouse, which exhibits a slow and progressive cerebellar degeneration (Wang et al., 2001).

The present study reports an essential role for Fz5 in the survival of mature neurons in the parafascicular nucleus (PFN) of the thalamus. The PFN and the adjacent centromedian nucleus provide major noncortical glutamatergic input to the striatum (Royce and Mourey, 1985; Sadikot et al., 1992a,b; Deschenes et al., 1996; Matsumoto et al., 2001; Yasukawa et al., 2004; Lacey et al., 2007; Smeal et al., 2007). The PFN also projects to the motor and anterior cingulate cortices (Vercelli et al., 2003; Parent and Parent, 2005). The PFN receives inputs from the spinal cord, the superior colliculus, the pedunculopontine tegmental nucleus, various vestibular nuclei, and the substantia nigra pars reticulata (Royce et al., 1991; Shiroyama et al., 1995; Kobayashi and Nakamura, 2003; Nakamura et al., 2006). The functions of the PFN are still only partially understood: it has been implicated in the response to pain (Kaelber et al., 1975; Harte et al., 2000, 2004, 2005; Weigel and Krauss, 2004; Saade et al., 2007), in attentiondependent orientation (Minamimoto and Kimura, 2002), and in 
memory in the context of an odor discrimination task (QuirozPadilla et al., 2007). Interestingly, the PFN and the centromedian nucleus show substantial degeneration in postmortem brains from Parkinson's disease patients, whereas adjacent thalamic nuclei are unaffected (Xuereb et al., 1991; Henderson et al., 2000). In rats, unilateral ablation of the nigrostriatal pathway with 6-hydroxydopamine leads to a corresponding and highly specific loss of ipsilateral PFN neurons (Aymerich et al., 2006). These observations suggests that PFN neurons have a distinctive vulnerability and that their loss may contribute to the pathophysiology of Parkinson's disease.

\section{Materials and Methods}

Gene targeting. Fz 5 genomic clones were obtained from an Sv129 $\lambda$ phage genomic library (a gift from Dr. Se-Jin Lee, Johns Hopkins University, Baltimore, MD). To create the $F z 5^{\text {lac } Z}$ targeting vector, a lac $Z$ coding region with a $3^{\prime}$ untranslated region from the mouse protamine- 1 gene followed by a phosphoglycerate kinase (PGK)-Neo cassette was cloned between a $3.7 \mathrm{~kb}$ SpeI-EagI genomic fragment located immediately $5^{\prime}$ of the Fz5 open reading frame and a $3.8 \mathrm{~kb}$ EcoRI-BamHI genomic fragment located $3^{\prime}$ of the $F z 5$ coding region and encompassing part of the $F z 53^{\prime}$ untranslated region. The noncoding first exon of the Fz5 gene, the intron between exons 1 and 2, and part of the $5^{\prime}$ untranslated region sequence within exon 2 remained intact and was contained within the 3.7 $\mathrm{kb} 5^{\prime}$ arm of the targeting vector. To create the conditional knock-in $F z 5^{C K O-A P ; F N F}$ targeting vector, loxP sites were inserted at two sites: (1) within the second $\mathrm{Fz} 5$ exon 46 bp $5^{\prime}$ of the initiator methionine codon and (2) $\sim 0.7 \mathrm{~kb}$ distal to the polyA addition site. The $5^{\prime}$ loxP site was marked with a synthetic HindIII site so that its presence could be monitored by Southern blotting. The following DNA segments were added beyond the 3' loxP site: (1) the coding region for human placental alkaline phosphatase (AP), (2) a PGK-Neo cassette flanked by frt sites, and (3) the same $3.8 \mathrm{~kb} E c o$ RI-BamHI $3^{\prime}$ arm as described above. The 5' arm extended to an $\mathrm{HpaI}$ site $5.7 \mathrm{~kb}$ upstream of the $5^{\prime}$ loxP. A PGK promoterherpes simplex virus thymidine kinase gene was inserted beyond the right arm of each targeting vector for negative selection in embryonic stem (ES) cells. Each targeting vector was introduced by electroporation into R1 ES cells and plated in G418 and ganciclovir containing medium. ES colonies were screened for the correct targeting event by Southern blot hybridization with flanking probes, and targeted cells with a normal karyotype were injected into C57BL/6 embryos.

Mouse genetics and genotyping. Germline transmission of the Fz5 $5^{\text {lac } Z}$ and $F z 5^{C K O-A P ; F N F}$ alleles was confirmed by Southern blot hybridization. Mice carrying the $F z 5^{C K O-A P ; F N F}$ were crossed to germline Flp mice to excise the frt-Neo-frt cassette, and the resulting $\mathrm{Fz} 5^{\mathrm{CKO}-\mathrm{AP}}$ mice were bred to homozygosity. The Fz5 $5^{\text {lac } Z}$ line was crossed to Sox2-Cre (Hayashi et al., 2002, 2003) ( $\mathrm{Tg}$ (Sox2-cre)1Amc/J; The Jackson Laboratory) or to R26CreER (Badea et al., 2003) mice to generate, respectively, Fz $5^{\text {lacZ/+ }}$;Sox2Cre males or $\mathrm{Fz}^{\text {lacZ/+ }}$;R26-CreER males and females to cross with $\mathrm{Fz} 5^{\mathrm{CKO}-\mathrm{AP} / \mathrm{CKO}-\mathrm{AP}}$ homozygotes. The resulting crosses produced experimental (Fz5 $5^{\text {CKO-AP/lacZ; }}$ Sox2-Cre and Fz5 $5^{\text {CKO-AP/lacZ }} ;$ R26-CreER) and control $\left(\mathrm{Fz} 5^{\mathrm{CKO}-\mathrm{AP} /{ }^{+}}\right.$;Sox2-Cre and $\mathrm{Fz} 5^{\mathrm{CKO}-\mathrm{AP} /{ }^{+}}$;R26-creER) littermates in the expected 1:1 ratio.

Tissue processing, histochemistry, immunocytochemistry, and in situ hybridization. Embryonic day 8.5 (E8.5) and E10.5 embryos were fixed in PBS with $0.2 \%$ gluteraldehyde, $2 \%$ paraformaldehyde (PFA) for 5-bromo-4-chloro-3-indolyl- $\beta$-D-galactopyranoside (X-gal) staining (Wang et al., 2002). Vibratome sections $(200 \mu \mathrm{m})$ of whole heads (for prenatal mice) or of dissected brains (postnatal mice) were prepared and stained with X-gal or nitroblue tetrazolium/5-bromo-4-chloro-indolyl phosphate (NBT/BCIP) as described previously (Wang et al., 2002; Badea et al., 2003). Fresh-frozen brain sections $(20 \mu \mathrm{m})$ were fixed with 4\% PFA and stained with X-gal, NBT/BCIP, cresyl violet (Franklin and Paxinos, 1997), or mouse monoclonal anti-NeuN (neuronal-specific nuclear protein) (Mab 377; Millipore). For in situ hybridization, $15 \mu \mathrm{m}$ fresh-frozen brain sections were processed as described previously (Schaeren-Wiemers and Gerfin-Moser, 1993) with the following modifications: fresh-frozen sections were dried thoroughly, fixed with $4 \%$
PFA in PBS for 10 min, acetylated in DEPC-treated water, washed three times with DEPC-treated water, and air-dried for $1 \mathrm{~h}$. Hybridization with digoxygenin-labeled riboprobe was at $66^{\circ} \mathrm{C}$ overnight.

Quantifying the number of Fz5-expresssing PFN neurons in the postnatal day 1 brain. Brains were immersion fixed in 2\% PFA, 0.2\% gluteraldehyde in PBS for $4-6 \mathrm{~h}$ at $23^{\circ} \mathrm{C}$, and vibratome sectioned at $80 \mu \mathrm{m}$ in the coronal plane. After washing in PBS, the sections were stained with X-gal to visualize the PFN. For each brain, the region encompassing the PFN was dissected from each section, and these tissue samples were pooled and incubated with $0.5 \%$ trypsin-EDTA at $37^{\circ} \mathrm{C}$ for $\sim 90$ min with occasional mixing. Triton X-100 was added to $0.5 \%$, and the digested cells were gently dispersed by pipetting. The dissociated cells were recovered by low speed centrifugation, washed with PBS, and the number of X-galstained cells was quantified by counting three independent aliquots in a hemocytometer.

4-Hydroxytamoxifen treatment and quantification of PFN neuron loss. 4-Hydroxytamoxifen (4HT; Sigma) was dissolved in sunflower seed oil for intraperitoneal injection as described previously (Badea et al., 2003). Six-week-old $\mathrm{Fz}^{\mathrm{CKO}-\mathrm{AP} /+} ; \mathrm{R} 26-\mathrm{creER}$ and $\mathrm{Fz} 5^{\mathrm{CKO}-\mathrm{AP} / \mathrm{lac} Z} ; \mathrm{R} 26$-creER mice were injected intraperitoneally with $40 \mu \mathrm{g}$ of $4 \mathrm{HT} / \mathrm{g}$ body weight, and more than three mice of each genotype were analyzed for each time point in Figure 5 by NBT/BCIP staining of $20 \mu \mathrm{m}$ fresh-frozen sections. $\mathrm{AP}+$ cell bodies were counted from the central/anterior region of the PFN from three sections for each genotype and are presented as number of $\mathrm{AP}+$ cell bodies per section in Figure $5 \mathrm{H}$. For NeuN quantification of neurons (see Fig. $3 D, E$ ), sets of three adjacent $20 \mu \mathrm{m}$ sections from anterior, central, and posterior regions of the adult PFN (each set separated by $220 \mu \mathrm{m}$ ) were immunostained as described above.

Cell culture assay of canonical Wnt signaling. 293/Super TOP Flash (STF) cell transfection and luciferase assays were performed as described previously (Xu et al., 2004)

Behavioral testing. A variable speed rotorod apparatus was used to monitor the time elapsed before falling from the rotating wheel. The elapsed times for three $60 \mathrm{~s}$ trials were averaged for each mouse for each of three rotational velocities (one revolution per 3, 6, or $12 \mathrm{~s}$ ). Testing was repeated under infrared light and monitored with an infrared image converter to rule out effects of visual input on test performance. Grip strength was tested by determining for up to $15 \mathrm{~min}$ whether the mouse could support its weight by clinging upside down to a metal cage top. Free-running wheel activity was measured in a $12 \mathrm{~h}$ dark/light environment. For the tail-flick test, the distal one-third of the tail was immersed in a tube of water equilibrated at 47 or $50^{\circ} \mathrm{C}$ and the number of seconds that elapsed until a tail flick was recorded. For the hot plate test, the mouse was placed on a plate maintained at $50^{\circ} \mathrm{C}$ and the number of seconds that elapsed until hindfoot licking or lifting was recorded.

Microarray and RNA blot hybridization. Unfixed brains from young adult mice were embedded in 3\% agarose, and $200 \mu \mathrm{m}$ coronal sections were cut with a vibratome beginning at the anterior. As each section was cut, it was examined under indirect illumination to determine when the fasciculus retroflexus could be seen $(\sim 1 \mathrm{~mm}$ below the third ventricle). At this point, a single $450 \mu \mathrm{m}$ coronal section (containing most of the PFN) was cut from the exposed face of the brain, and from this section a $2 \times 2 \mathrm{~mm}$ square centered on the fasciculus retroflexus and encompassing the PFN was excised from each side of the thalamus. RNA was extracted using Trizol (Invitrogen) and an RNeasy kit (Qiagen) following the manufacturers' protocols. RNA blotting was performed using standard methods with ${ }^{32} \mathrm{P}$-labeled probes, PCR amplified from the $3^{\prime}$ noncoding regions of the indicated genes. Three independent dissections of the PFN from $\mathrm{Fz}^{-/-}$and from $\mathrm{Fz}^{+/-}$brains were used in microarray experiments with mouse genome 4302.0 microarrays (Affymetrix). Data were processed as described previously (Chen et al., 2005).

\section{Results \\ Constitutive and conditional deletions of the $\mathrm{Fz} 5$ coding region}

In an initial approach to studying $F z 5$ expression and function in mice, we replaced the $F z 5$ coding region, which conveniently resides on a single exon, with a DNA segment coding for a 

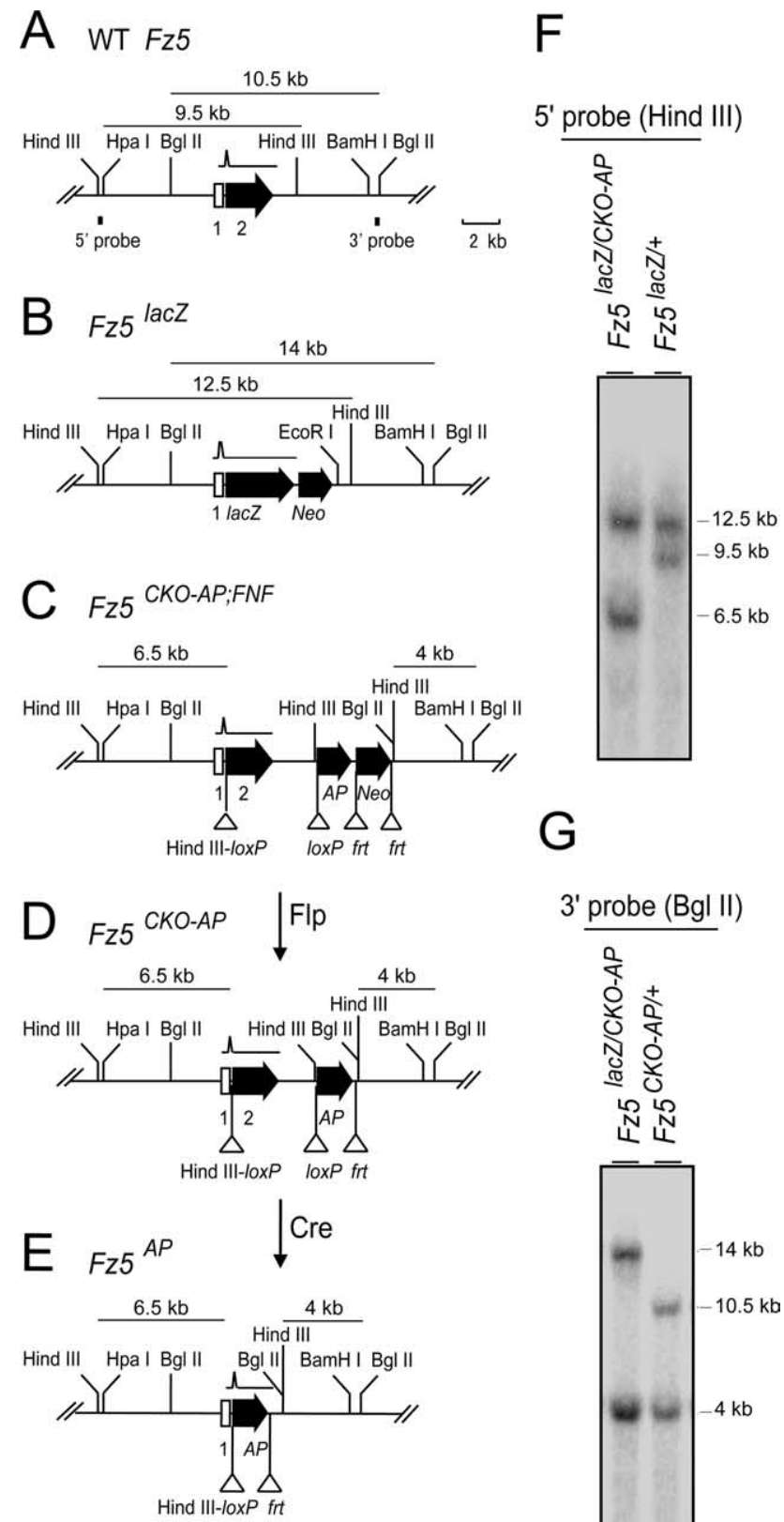

Figure 1. Targeted mutations at the $F z 5$ locus. $A$, The WT $F z 5$ locus consists of a 5 ' noncoding exon and a $3^{\prime}$ exon containing the complete $F z 5$ coding region. $\boldsymbol{A}-\boldsymbol{E}$, A schematic of the spliced mRNA is shown above the WT or targeted Fz5 gene. $5^{\prime}$ and $3^{\prime}$ Southern blot hybridization probes, derived from regions beyond the edges of the targeting constructs, are indicated. $\boldsymbol{B}$, Replacement of $F z 5$ coding sequences with the Escherichia coli lac $Z$ coding region followed by a PGK-Neo selectable marker. C, F 75 conditional knock-out allele with the following elements (from $5^{\prime}$ to $3^{\prime}$ ): a Hind III-tagged loxP site in the second exon $5^{\prime}$ of the initiator methionine codon, a second loxP site $3^{\prime}$ of the transcription unit, an AP open reading frame, and a PGK-Neo cassette flanked by frt sites. $\boldsymbol{D}$, The $F z 5$ conditional knock-out allele after excision of the $P G K$-Neo cassette by $F / p$ recombinase. $E$, Starting with the $F z 5$ conditional knock-out allele, site-specific excisions by both Flp and Cre results in the replacement of the $F z 5$ coding region with the $A P$ coding region. $\boldsymbol{F}, \boldsymbol{G}$, Whole-genome Southern blot hybridization confirms the WT and targeted FZ5 gene structures shown in $\boldsymbol{A}-\boldsymbol{E}$. The locations of the $H$ ind III and $B g / l l$ restriction fragments visualized by whole-genome Southern blotting with the $5^{\prime}$ and $3^{\prime}$ probes, respectively, are shown by horizontal lines above $\boldsymbol{A}-\boldsymbol{E}$.

$\beta$-galactosidase reporter ( $F z 5^{\text {lac } Z}$ ) (Fig. 1). Ishikawa et al. (2001) had reported previously that $F z 5^{-/-}$mice die at midgestation because of placental insufficiency, and we observed the same lethal phenotype with $F z 5^{\text {lacZ/lac } Z}$ homozygotes. To study the role of
Fz5 at developmental times beyond this stage, we constructed a conditional allele in which one loxP site was inserted within the single Fz5 coding exon $5^{\prime}$ of the initiator methionine codon, and a second loxP site was inserted distal to the $3^{\prime}$ untranslated region and polyadenylation site. This conditional allele also carries coding sequences for an AP reporter immediately downstream of the 3' loxP site (Fz5 $\left.5^{C K O-A P}\right)$ (Fig. 1). Thus, Cre-mediated excision of the Fz5 coding and $3^{\prime}$ untranslated regions should lead to AP expression under the control of $F z 5$ transcriptional regulatory sequences.

Control experiments confirmed that the unrecombined $F z 5^{C K O-A P}$ allele behaves as a wild-type (WT) allele, and that Cremediated recombination directed by a Sox2-Cre transgene (Hayashi et al., 2002, 2003) leads to efficient excision of Fz5 coding sequences. In the experiments described below, Cre-mediated recombination of the $F z 5^{C K O-A P}$ allele was controlled by either (1) a paternally inherited Sox2-Cre transgene that recombines in embryonic, but not extraembryonic, tissues starting at $\sim \mathrm{E} 8$, thus bypassing the midgestational lethality associated with loss of Fz5 function in extraembryonic tissues, or (2) a gene encoding a fusion between Cre recombinase and a modified ligand-binding domain of the estrogen receptor (CreER) targeted to the Rosa26 locus (R26-CreER) (Badea et al., 2003). In the latter case, systemic (i.p.) delivery of $4 \mathrm{HT}$ activated Cre-mediated recombination at a defined time in development or adulthood. R26-CreER is expressed ubiquitously or nearly so, but recombination of the $F z 5^{C K O-A P}$ allele by $R 26-C r e E R$ and $4 \mathrm{HT}$ is relatively inefficient, even with high doses of $4 \mathrm{HT}$ (up to $320 \mu \mathrm{g} / \mathrm{g}$ body weight). Thus, we have used R26-CreER to study cell-autonomous effects following the production of a sparse set of homozygous $\mathrm{Fz}^{-/-}$cells in a tissue environment in which the majority of the surrounding cells remain $\mathrm{Fz}^{+/-}$and phenotypically WT. In contrast, Sox2Cre recombines the $F z 5^{C K O-A P}$ target with nearly $100 \%$ efficiency.

In general, the experiments described below were performed with littermates from crosses that produced both control (e.g., $\mathrm{Fz} 5^{\mathrm{CKO}-\mathrm{AP} /+}$;Sox2-Cre or $\mathrm{Fz} 5^{\text {lacZ/+ }}$;Sox2-Cre) and experimental (e.g., $F z 5^{C K O-A P / l a c Z}$;Sox2-Cre) mice. We note that the formal genetic nomenclature, as written in the preceding sentence, defines the $F z 5$ alleles before Cre-mediated recombination. For clarity, we will refer below to $\mathrm{Fz}^{\mathrm{CKO}-\mathrm{AP} /+}$; Sox2-Cre as $\mathrm{Fz}^{+/-}$and $\mathrm{Fz} 5^{\mathrm{CKO}-\mathrm{AP} / \mathrm{lac} Z}$; Sox2-Cre as $\mathrm{Fz} 5^{-/-}$to indicate the actual tissue genotype that results from Sox2-Cre-mediated recombination. With respect to the use of $F z 5$ heterozygotes as controls, we have observed no differences between $\mathrm{Fz}^{+/-}$and $\mathrm{Fz}^{+/+}$mice and we therefore consider the phenotype of $\mathrm{Fz}^{+/-}$to be representative of the WT.

Restricted expression of $\mathrm{Fz} 5$ in the developing and adult CNS Histochemical analyses of reporter gene expression in $\mathrm{Fz} 5^{\text {lac } Z /+}$ and $F z 5^{A P /+}$ mice were used to produce a comprehensive view of Fz5 gene expression throughout development (Fig. 2). The two alleles produce nearly identical patterns of reporter localization, the only difference being that $\beta$-galactosidase accumulates principally in neuronal cell bodies whereas AP, a glycosylphosphatidylinositol (GPI)-anchored plasma membrane protein, also accumulates efficiently on dendrites and axons.

At E8.5, Fz5 is expressed exclusively in the neural ridge, the anterior-most region of the neural plate (Fig. 2A). By E10.5, Fz5 expression is seen in the ventral telencephalon and optic vesicles, as well as in the midgut and hindgut (Fig. 2B). By late gestation, $\mathrm{Fz} 5$ expression in the CNS is mostly confined to the retina, the hypothalamus, and the PFN of the thalamus (Fig. 2C,E,F). This pattern of $F z 5$ expression persists throughout postnatal life (Fig. 

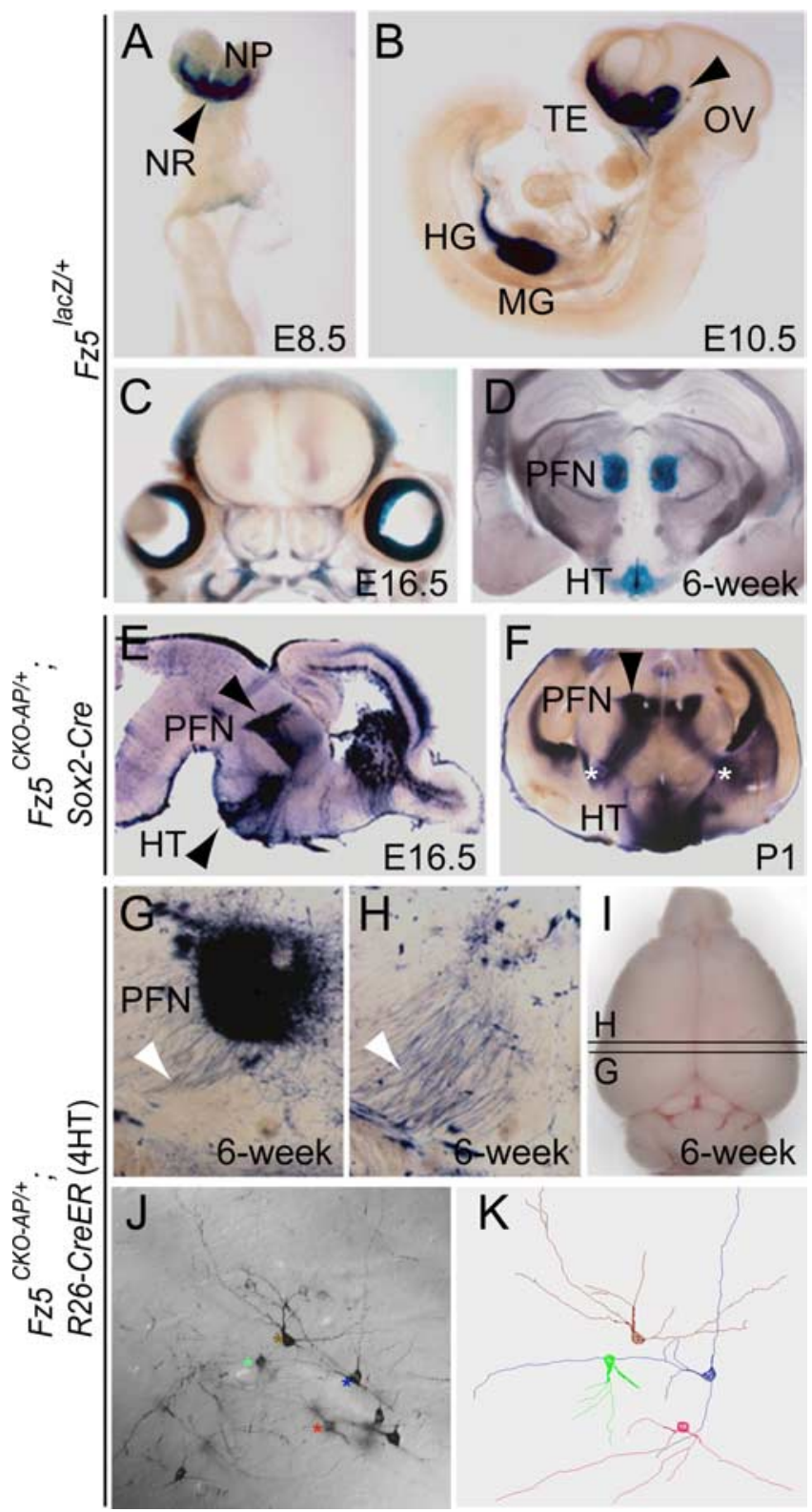

Figure 2. Highly restricted expression of the $F z 5$ gene during development and in adulthood. $A, B, X$-gal-stained whole mounts of $F z 5^{\text {lacz/+ }}$ embryos show $F z 5$ expression in the neural ridge (NR) at the anterior of the neural plate (NP) at E8.5 ( $\boldsymbol{A}$ ) and in the telencephalon (TE), optic vesicle (OV), hindgut (HG), and midgut (MG) at E10.5 (B). C, D, X-gal-stained coronal vibratome sections of $F_{7} 5^{\mathrm{lac} / \mathrm{H}}$ heads show $F_{72}$ expression in the retinas at E16.5 $(\boldsymbol{C})$ and in the PFN and hypothalamus (HT) at 6 weeks of age (D). E, F, NBT/BCIP staining of vibratome sections of $\mathrm{FZ}_{5} 5^{\mathrm{CKO}-\mathrm{AP} /{ }^{+}}$;Sox2-(re $\left(\mathrm{Fz}^{+/-}{ }^{-}\right)$brains. A sagittal section atE16.5 (E) and a coronal section at P1 $(\boldsymbol{F})$ show $F z 5$ expression in the PFN and hypothalamus. A fiber tract, marked by an asterisk in $\boldsymbol{F}$, originates in each PFN and courses inferiorly, laterally, and anteriorly to the ipsilateral striatum. $\boldsymbol{G}-\boldsymbol{I}$, Coronal sections through the PFN $(\boldsymbol{G})$ and just anterior to the PFN $(\boldsymbol{H})$ from a 6-week-old $\mathrm{F}_{7} 5^{\mathrm{CKO}-\mathrm{AP} /{ }^{+}} ; \mathrm{R26-CreER}$ mouse injected intraperitoneally $14 \mathrm{~d}$ earlier with $40 \mu \mathrm{g} / \mathrm{g}$ 4HT and stained with NBT/BCIP. The locations of the two sections are shown in $I$. White arrowheads, APlabeled axons coursing from the PFN to the striatum. $\boldsymbol{J}, \boldsymbol{K}$, Morphologies of $F_{7} 5^{A P}$-expressing PFN neurons after sparseCre-mediated recombination in an NBT/BCIP-stained $200 \mu$ m vibratome section from an $\mathrm{F}_{25} \mathrm{CKO}^{\mathrm{KP} /{ }^{+}} ; \mathrm{R} 26$-creER mouse injected at 6 weeks of age with $40 \mu \mathrm{g} / \mathrm{g}$ 4HT.J, DIC image at a single focal plane with the cell bodies of four neurons indicated by colored asterisks. $\boldsymbol{K}$, Neurolucida tracing of these four neurons from a stack of $2001 \mu \mathrm{m} Z$-series sections.

$2 D)$. In coronal sections, the PFN presents a highly distinctive appearance because its medial aspect surrounds the fasciculus retroflexus (the habenulo-interpeduncular tract) (Fig. 2D,F,G). Within the PFN, Fz5 expression is confined to neurons as deter- mined by reconstructing the morphologies of AP-expressing cells visualized in vibratome sections after sparse Cre-mediated recombination in $\mathrm{Fz}^{\mathrm{CKO}-\mathrm{AP} /+} ; \mathrm{R} 26$-creER mice (Fig. $2 \mathrm{~J}, \mathrm{~K}$ ). APlabeled PFN axons project predominantly to the ipsilateral striatum (Fig. 2F-I, supplemental Fig. 1, available at www. jneurosci.org as supplemental material). These observations extend previous in situ hybridization analyses of $F z 5$ expression in the developing and adult retina and brain (Wang et al., 1996; Shimogori et al., 2004).

\section{Late loss of $\mathrm{Fz} 5$-expressing neurons in the parafascicular nucleus of $\mathbf{F z 5}$-deficient mice}

Fz5 $5^{\text {CKO-AP/lacZ }}$;Sox2-Cre $\left(F z 5^{-/-}\right)$mice survive to adulthood, with no apparent deficiencies in fertility or general health. In external appearance they differ from their $\mathrm{Fz}^{+/-}$littermates by only a $15-20 \%$ reduction in size and weight (described more fully below). Histological analyses show two CNS regions that differ between adult $\mathrm{Fz}^{-/-}$and control $\mathrm{Fz}^{+/-}$mice: the retina, which exhibits a slowly progressive degeneration, and the PFN, which shows a loss of $\sim 50 \%$ of all neurons, as determined by Nissl staining or anti-NeuN immunostaining, and nearly $100 \%$ of the Fz5-expressing neurons (Fig. 3A-E). This PFN phenotype is the subject of the present study. Interestingly, the hypothalamus, where $F z 5$ is strongly expressed, shows no apparent histological defect (Fig. $3 A-C$ ), although the smaller average size and weight of $\mathrm{Fz}^{-/-}$mice suggests that hypothalamic function may be impaired. The nearly complete loss of $F z 5$ reporter gene expression in the PFN of $\mathrm{Fz}^{-/-}$mice (Fig. $3 \mathrm{~B}, \mathrm{C}$ ) is unlikely to arise from a secondary downregulation of $F z 5$ promoter activity because, as described more fully below, $F z 5$ reporter expression persists for several weeks in the $F z 5^{-/-}$PFN and only declines when PFN neurons are lost later in life. Molecular changes in the $\mathrm{Fz}^{-/-}$ PFN were identified by in situ hybridization with probes derived from genes expressed in the WT PFN (Lein et al., 2007). Five such hybridization analyses are shown in Figure $3 F-J$, and in each case they reveal a complete or nearly complete loss of transcripts in the $\mathrm{Fz}^{-/-}$PFN. The probes include Neurexophilin (Nxph1), cartilage acidic protein 1 (Crtac1), protocadherin $20(\operatorname{Pcdh} 20)$, a protein of unknown function (BC085092), and Wnt4, an Fz ligand.

The absence of $F z 5$-expressing adult PFN neurons led us to ask when in development this cell loss occurs. Surprisingly, we found that Fz5 is required only for the postnatal survival but not the birth and overall development of PFN neurons: in early postnatal $\mathrm{Fz}^{-1-}$ mice, PFN neurons are present in normal numbers [as determined by counting dissociated X-gal-stained neurons from the dissected PFN of P1 Fz5 $5^{\text {CKO-AP/lacZ }}$;Sox2-Cre $\left(F z 5^{-/-}\right)$and $\mathrm{F} z 5^{\text {lacZ/+ }}$ mice (data not shown)] and they project to the striatum in a manner indistinguishable from WT PFN neurons (Fig. $4 A, B)$. PFN neurons are then gradually lost during the first postnatal month (compare Figs. 3C, $4 B$ ). Despite the apparently normal development of the $F z 5^{-/}$PFN, in situ hybridization to sections of postnatal day 2 (P2) brain using the five probes shown in Figure $3 F-J$ shows for each transcript a decrease in abundance in the PFN (Fig. 4C-E, the three transcripts with the most obvious decrements are shown; the decrements for the $\operatorname{Pcdh} 20$ and Nxph1 transcripts are less obvious).

Continuous and cell-autonomous requirement for $\mathrm{Fz} 5$ in the survival of parafascicular nucleus neurons

The progressive postnatal loss of $\mathrm{Fz}^{-/-}$PFN neurons in mice that were rendered $\mathrm{Fz}^{-/-}$from the earliest stages of embryonic development (i.e., genotype $\mathrm{Fz}^{\mathrm{CKO}-\mathrm{AP} / \mathrm{lac}}$;Sox2-Cre) does not necessarily mean that neuronal survival requires ongoing Fz5 


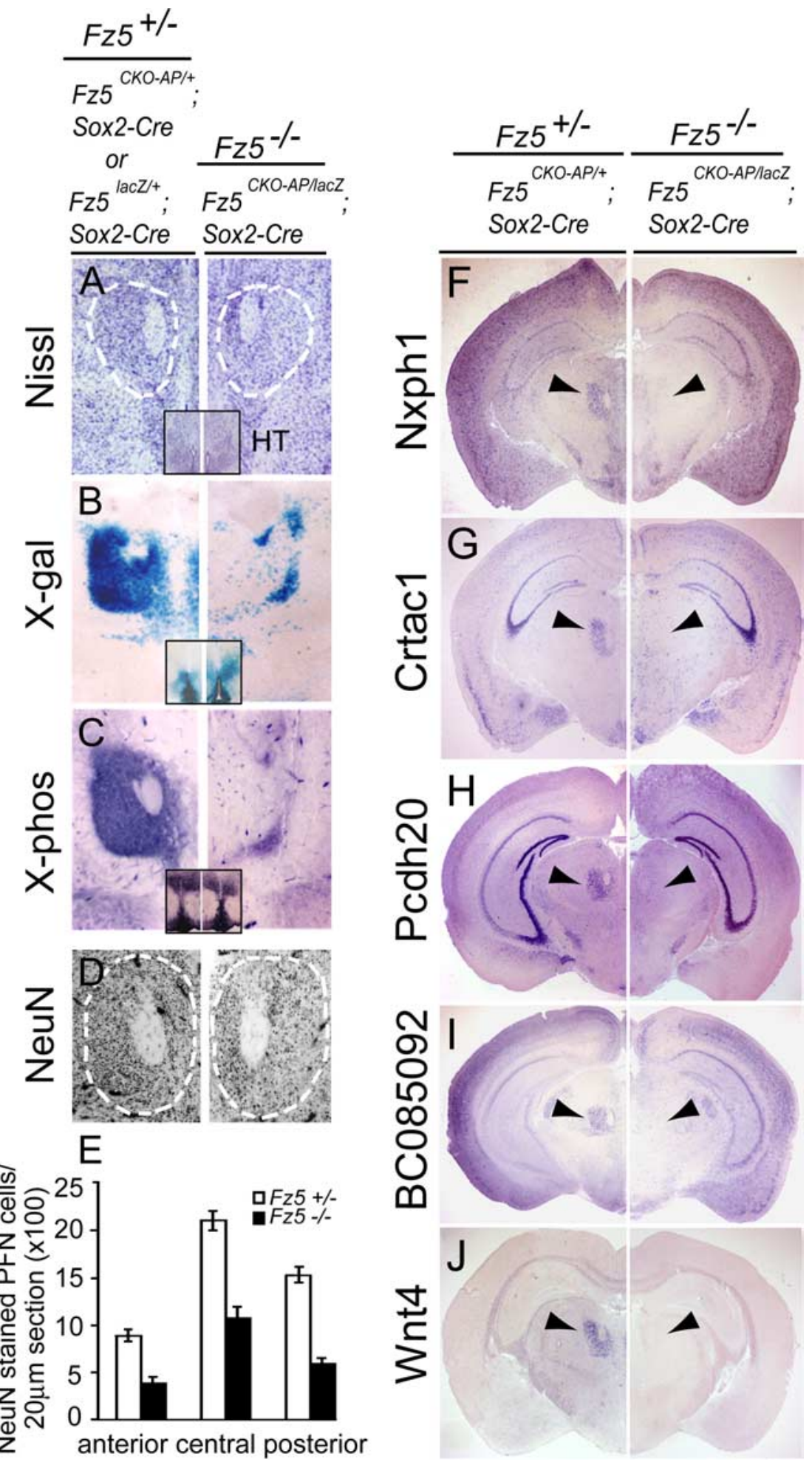

Figure 3. Progressive loss of neurons in the postnatal $F_{72} 5^{-/-}$PFN. A-E, Nissl, X-gal, NBT/BCIP, and anti-NeuN staining of

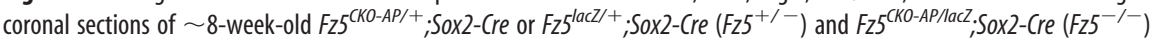
brains showing the PFN region of the thalamus. $A-C$, Insets, The hypothalamic region from the same sections, which has equivalent cell densities and levels of $F z 5$ expression in $F_{75} 5^{+\prime-}$ and $F_{72} 5^{-/-}$brains. $A, D$, The PFN is outlined by white dashes. A, C, D,

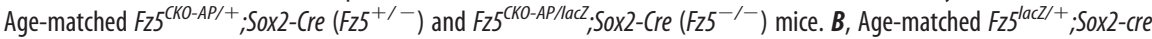

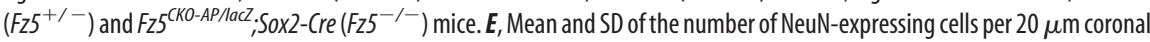
section in the anterior, central, and posterior regions of the PFN, as delimited in $\boldsymbol{D}$ ( 3 sections/sample). $\boldsymbol{F}-\boldsymbol{J}$, In situ hybridization with the indicated probes to coronal sections through the PFN region of the thalamus from age-matched adult $\mathrm{F}_{7} 5^{\mathrm{CKO}-\mathrm{AP} /{ }^{+}} ; \mathrm{SOX} 2-$

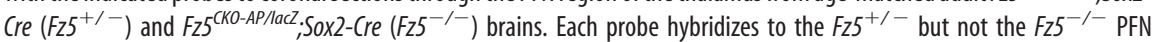
(arrowheads). The abbreviated probe names and National Center for Biotechnology Information accession numbers are Nxph1 (BC079608), Crtac1 (BC024472), Pcdh20 (BC024927), and BC085092, unknown protein (BC085092). function. Instead, the absence of Fz5 during an early developmental time window could lead to a lasting defect in some aspect of neuronal structure or function (for example, the formation of correct synaptic contacts) that leads to a loss of neuronal viability later in life. The progressive loss of PFN neurons in $\mathrm{Fz}^{-/-}$mice also does not distinguish between cell autonomous and nonautonomous effects because, in these mice, all of the PFN neurons are $\mathrm{Fz}^{-1-}$. As one example of a nonautonomous mechanism, a high local density of physiologically compromised $\mathrm{Fz}^{-1-}$ PFN neurons could lead to local suprathreshold excitotoxicity, as has been shown to occur in stroke and other focal CNS insults (Lee et al., 1999).

To address these questions, we asked whether, in the phenotypically normal adult brain, a synchronous conversion of a sparse subset of PFN neurons from $\mathrm{Fz}^{+/-}$ to $\mathrm{Fz}^{-/-}$leads to their death. To both create and visualize the recombined neurons, this experiment required the following three components: (1) the $F z 5^{C K O-A P}$ allele, in which a reporter (AP) marks only those $F z 5$-expressing cells that have undergone Cre-mediated recombination; (2) the $F z 5^{\text {lac } Z}$ allele, which does not express $\mathrm{AP}$, and which is used in a compound heterozygous combination with the $\mathrm{Fz} 5^{\mathrm{CKO}-\mathrm{AP}}$ allele so that recombination of only a single allele is required to affect the conversion from $\mathrm{Fz}^{+/-}$to $\mathrm{Fz} 5^{-/-}$; and (3) exposure of the $F z 5^{C K O-A P}$ allele to the action of a ubiquitously expressed CreER recombinase during a brief time window defined by a single intraperitoneal injection of $4 \mathrm{HT}$. Previous work has indicated that a single bolus of $4 \mathrm{HT}$ delivered systemically persists at concentrations sufficient to activate CreER for not more than 24-48 h (Lobe et al., 1999; Badea et al., 2003), a time window that sets the temporal resolution of this experiment.

In the PFN of adult $F z 5^{\text {CKO-AP/lacz }} ; R 26-$ CreER and $\mathrm{Fz}^{\mathrm{CKO}-\mathrm{AP} /+} ; \mathrm{R} 26-$ creER mice not exposed to $4 \mathrm{HT}$, there are, respectively, no AP-expressing neurons and fewer than $10 \mathrm{AP}$-expressing neurons per $200 \mu \mathrm{m}$ vibratome section. For both genotypes, a single intraperitoneal injection of $40 \mu \mathrm{g} / \mathrm{g} 4 \mathrm{HT}$ in adulthood results in the rapid appearance of a large number of APexpressing PFN neurons. In $\mathrm{Fz} 5^{\mathrm{CKO}-\mathrm{AP} / \mathrm{lac} \text {; }}$ R26-CreER mice, these acutely recombined and AP-expressing (i.e., $\mathrm{Fz}^{-1-}$ ) PFN neurons are progressively lost over a period of several days after $4 \mathrm{HT}$ injection (Fig. $5 A-D, H$ ). In contrast, AP-expressing $\mathrm{Fz}^{+/-}$neurons in the brains of control $F z 5^{C K O-A P /+} ; R 26-$ creER littermates appear 
unchanged $8 \mathrm{~d}$ after $4 \mathrm{HT}$ injection. Ten days after $4 \mathrm{HT}$ injection, serial sectioning shows a nearly complete loss of APexpressing $\mathrm{Fz}^{-/-}$neurons over the full extent of the $\mathrm{Fz} 5^{\mathrm{CKO}-\mathrm{AP} / \mathrm{lacZ}}$;R26-CreER PFN (Fig. 5E-G). Interestingly, $4 \mathrm{HT}$ injection also activates AP expression in glia that are scattered throughout the brain in both Fz $5^{\text {CKO-AP/lacZ; }}$ R26-CreER and $\mathrm{Fz}^{\mathrm{CKO}-\mathrm{AP} /+}$; R26-creER mice (Fig. 5E-G).

The relatively sparse recombination obtained with $R 26-C r e E R$ and $4 \mathrm{HT}$ precludes an assessment of cell loss based on quantification of the total number of NeuN- or Nissl-stained cell bodies, as was possible in $\mathrm{Fz}^{-/-}$brains (Fig. 3A-E). However, based on the previous observation that the absence of Fz5 does not affect the expression of the AP reporter expressed from $F z 5^{A P}$ in prenatal or early postnatal PFN neurons in $\mathrm{Fz}^{-1-}$ mice (Figs. 2, 3), we infer that the rapid 4HT-dependent extinction of the AP signal within the PFN in the $F z 5^{C K O-A P / l a c Z}$; R26-CreER experiment cannot be explained by an Fz5 dependence of Fz5 expression, but rather reflects the rapid elimination of the subset of neurons that were acutely converted from $\mathrm{Fz}^{+/-}$to $\mathrm{Fz}^{-1-}$ and that were expressing AP immediately before their demise. Thus, this experiment demonstrates an ongoing and cell autonomous requirement for $F z 5$ expression in the survival of PFN neurons. Whether nonrecombined neurons in the PFN or elsewhere are adversely affected by the loss of individual Fz5-requiring PFN neurons is unknown. As expected from the analysis of $F z 5^{-/-}$brains (Fig. 3), acutely recombined and AP-expressing $F z 5^{-/-}$cells in the $F z 5^{C K O-A P / l a c Z}$; R26-CreER hypothalamus appear unaltered by the loss of Fz5 (Fig. 5A-C,E-G).

\section{Motor coordination defects in Fz5-deficient mice}

As noted above, $\mathrm{Fz} 5^{-/-}$mice are smaller than their $\mathrm{F} z 5^{+/-}$littermates, an effect that is evident from the first postnatal week and continues throughout life (Fig. 6A). Despite their reduced size and weight, $\mathrm{F} 5^{-1-}$ mice are indistinguishable from control littermates in grip strength during a 15 min suspension test, in their response to handling, and in the rate of spontaneous wheel running per $24 \mathrm{~h}$ (Fig. $6 \mathrm{~B}$ ). They are also indistinguishable from control littermates in the tail-flick test of thermal pain, a spinal reflex to noxious stimuli, and in paw withdrawal from a hot plate (data not shown) (Crawley, 2000). The only behavioral/motor test in which we have observed a reproducible difference between $\mathrm{Fz}^{-1-}$ and $\mathrm{Fz}^{+/-}$littermates is the rotorod, in which $\mathrm{Fz}^{-1-}$ mice show a clear deficit in motor coordination (Fig. 6C). The differential in rotorod performance was also maintained when the testing was conducted under infrared illumination, ruling out any role for visual impairment in the compromised performance of $\mathrm{Fz}^{-/-}$mice. Although impaired rotorod performance could reflect cerebellar dysfunction, Fz5 is not expressed at detectable levels in the cerebellum, as determined by X-gal staining of $\mathrm{Fz}^{\text {lacZ/+ }}$ and $\mathrm{Fz} 5^{\mathrm{CKO}-\mathrm{AP} / \mathrm{lac} Z}$;Sox2-Cre brains, and the cerebellum appears to be morphologically normal in $\mathrm{Fz}^{-/-}$mice. More
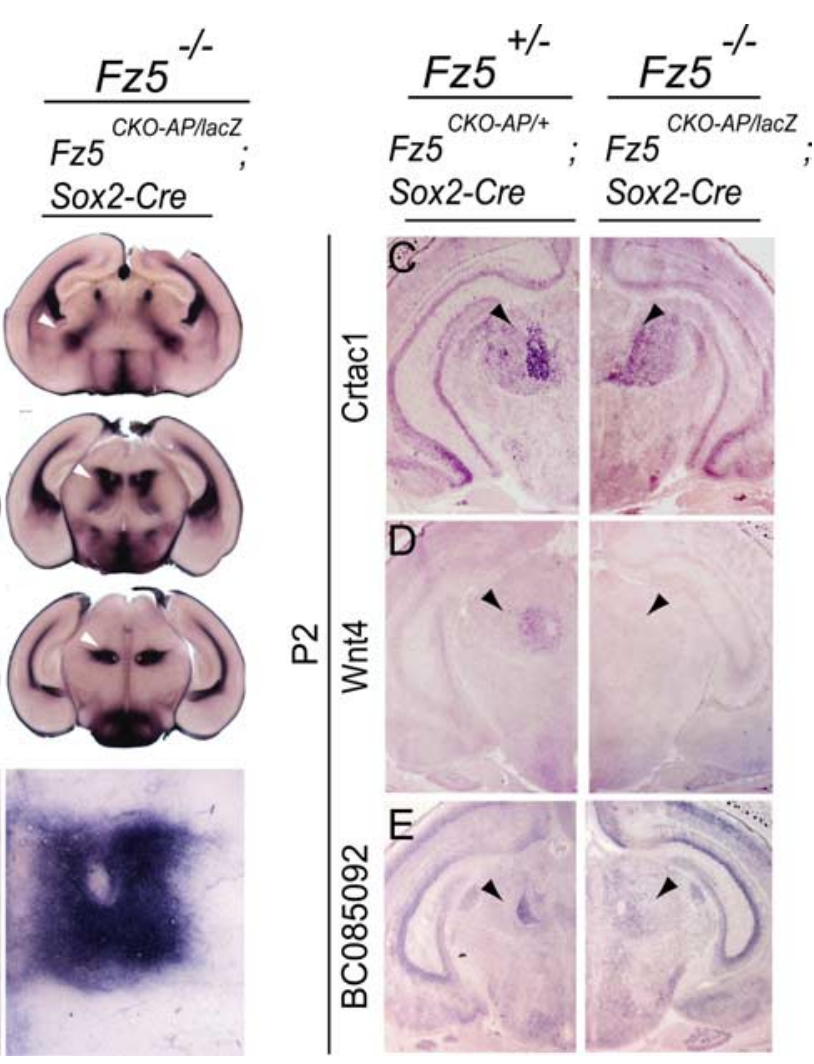

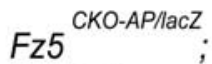
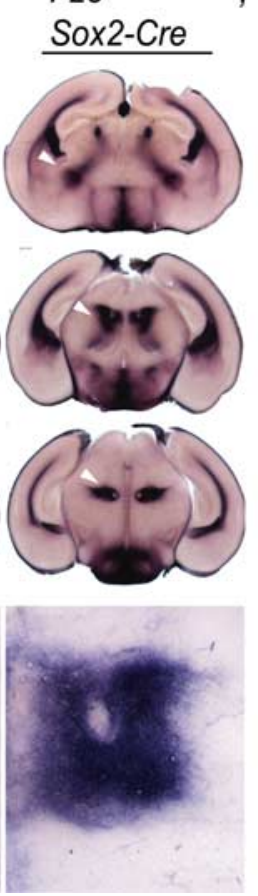


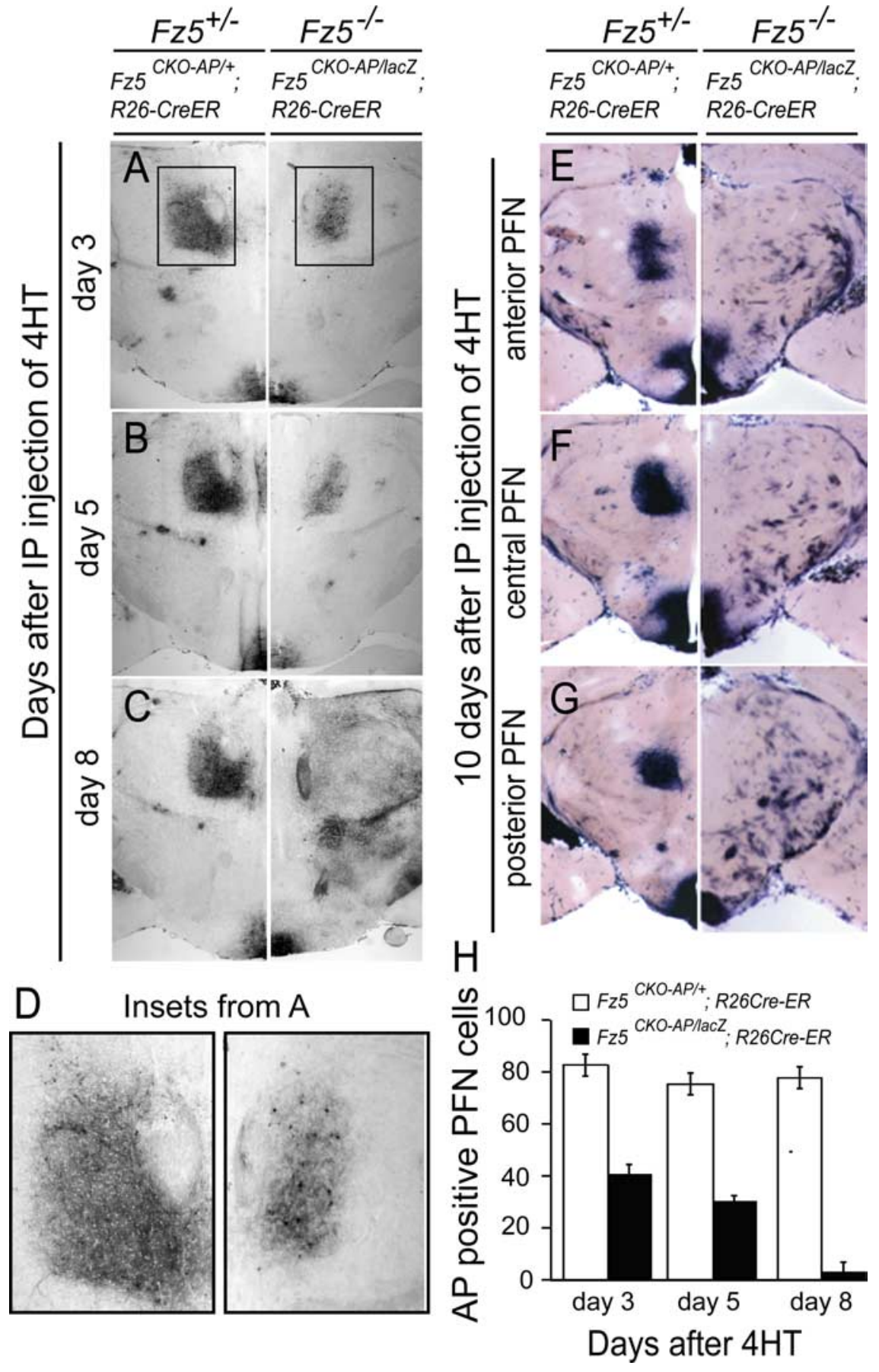

Figure 5. Rapid loss of adult PFN neurons after timed deletion of the $F z 5$ coding region. $A-D, A$ single intraperitoneal injection of $40 \mu \mathrm{g} / \mathrm{g} 4 \mathrm{HT}$ in adult $\mathrm{F}_{25} 5^{\mathrm{CKO}-A P /+}, R 26$-creER mice induces (re-mediated recombination, which generates a large number of $A P$-expressing $\mathrm{Fz}^{+} 5^{+/-}$PFN neurons with little or no loss of cell viability. The same $4 \mathrm{HT}$ treatment in $\mathrm{Fz} 5^{\mathrm{CKO}-\mathrm{AP} / \mathrm{lacZ}} ; \mathrm{R26}$-CreER mice is followed by a rapid loss of $A P$-expressing $F z 5^{-/-}$neurons. The boxed regions in $A$, which are enlarged in $D$, show the loss of AP-expressing neurons within $3 \mathrm{~d}$ of $4 \mathrm{HT}$ injection. $\boldsymbol{E}-\mathbf{G}$, Ten days after a single intraperitoneal injection of $40 \mu \mathrm{g} / \mathrm{g} 4 \mathrm{HT}$ in adulthood, AP-expressing $\mathrm{FZ}_{7} 5^{-1-}$ PFN neurons are eliminated throughout the anterior-posterior extent of the $\mathrm{Fz}_{7} 5^{C K O-A P / l a c Z}$; $R 26$-creER PFN, but AP-expressing $\mathrm{F}_{7} 5^{+/-}$neurons persist throughout the $\mathrm{F}_{2} 5^{C K O-A P /+} ; R 26$-creER PFN. As seen at the bottom of $\boldsymbol{A}-\boldsymbol{C}$ and $\boldsymbol{E}-\boldsymbol{G}, 4 \mathrm{HT}$ exposure in adulthood leads to equivalently efficient induction of AP-expressing cells in the hypothalamus in

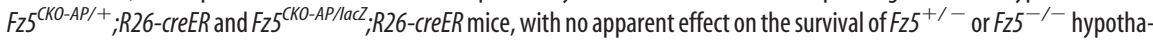
lamic cells. $\boldsymbol{H}$, Mean \pm SD of the number of $A P$-expressing cell bodies in three $20 \mu \mathrm{m}$ sections of the PFN after $4 \mathrm{HT}$ injection; data were obtained from the experiment shown in $\boldsymbol{A}-\boldsymbol{C}$.

transcripts exhibiting a more than twofold increase in abundance with loss of Fz5 (Fig. 7 A, B, supplemental Table 1, available at www.jneurosci.org as supplemental material). As expected, the $F z 5$ transcript was present in the set with reduced abundance in the $F z 5^{-/-}$PFN (Fig. 7A).
To independently assess differences in transcript abundance between the $\mathrm{F} 5^{-1-}$ and $\mathrm{Fz}^{+/-}$PFN as initially determined by in situ or microarray hybridization, RNA prepared from dissected and pooled PFN tissue was analyzed by Northern blot hybridization. Figure $7 C$ confirms the decrease in abundance of eight transcripts in the $\mathrm{Fz}^{-/-} \mathrm{PFN}$, and shows that the differential abundance estimated from the relatively low-stringency microarray hybridization generally underestimates the actual abundance change. Interestingly, among the transcripts with the greatest relative increase in the $F z 5^{-/-}$PFN are those coding for two embryonic $\beta$-like globins and an embryonic $\alpha$-like globin (supplemental Table 1, available at www.jneurosci.org as supplemental material). These transcripts do not appear to derive from contaminating blood cells as their abundances were unchanged in an analogous microarray comparison of $\mathrm{Fz} 5^{-/-}$and $\mathrm{Fz}^{+/-}$bone marrow-derived RNA, which contains a considerably larger proportion of blood cells than does brain (data not shown). This observation suggests that loss of the Fz5expressing PFN neurons is accompanied by a local induction of embryonic hemoglobins in the remaining neurons and/or surrounding glia.

\section{Evidence for canonical Wnt signaling mediated by $\mathrm{Fz} 5$ and Wnt9b}

One of the central unanswered questions in mammalian Wnt-Fz signaling is which Wnt ligand binds to which Frizzled receptor in different in vivo situations. Attempts to answer this question have been hampered by difficulties in obtaining recombinant Wnts in soluble form for binding and signaling assays, and by the overlap in expression and the corresponding redundancy in function among the 19 Wnts and 10 Frizzleds. To narrow the set of candidate Wnt ligands for Fz5 in the PFN, we began by surveying publicly available Wnt in situ hybridization data to identify Wnts that are expressed in the PFN (Shimogori et al., 2004; Lein et al., 2007). These data suggested that Wnt3a, Wnt4, Wnt5a, Wnt7, Wnt9b, and Wnt11 might meet this criterion; our subsequent in situ hybridizations using probes for these six Wnts further narrowed the field to Wnt 4 and Wnt9b, both of which are expressed in the early postnatal and adult PFN (Figs. 3J, $4 D, 8 C, D)$. Probes for the remaining four Wnts either do not hybridize to the PFN or do not produce a sufficiently intense hybridization signal to permit an assessment of the anatomic distribution of the corresponding transcripts in this region of the thalamus. We note that Lein et al. (2007) have reported low-level 
expression of Wnt1, Wnt7b, Wnt8a, and Wnt10b widely throughout the brain, including the striatum, and expression of Wnt 2 in a more restricted pattern, including the striatum. If Fz5 is present on PFN axon terminals, one or more of these Wnts could initiate signaling within the striatum.

As described above, several transcripts, including the Wnt4 transcript, are dramatically downregulated in the $\mathrm{Fz}^{-/-}$ $\mathrm{PFN}$ at P2, an age that precedes the loss of PFN neurons (Fig. $4 C-E$ ). Interestingly, transcripts coding for $\beta$-catenin and Wnt$9 \mathrm{~b}$, two other components that are very likely ( $\beta$-catenin) or possibly (Wnt9b) involved in Fz5 signaling are similarly downregulated in the $\mathrm{Fz}^{-/-} \mathrm{PFN}$ both at $\mathrm{P} 2$ and at 8 weeks of age (Fig. 8).

To test whether Wnt4 or Wnt-9b can activate canonical signaling via Fz5, we transfected plasmids coding for Wnt4 or Wnt9b, Fz5, and Lrp6 (one of two coreceptors) into 293/STF cells, a stable line in which multimerized LEF/T-cell factorbinding sites drive expression of a luciferase reporter (Xu et al., 2004). For Wnt9b, synergy in canonical Wnt pathway activation is seen in comparing 293/STF cells expressing all three proteins with 293/ STF cells expressing pairwise combinations of these proteins or each of these proteins individually (Fig. 9A). Analogous experiments with Wnt4 showed no affect of Wnt4 on luciferase activity when Wnt4 alone, Wnt4 and Fz5, or Wnt4, Fz5, and Lrp6 were transfected into 293/STF cells (data not shown). To examine the Frizzled specificity of Wnt9b activation, 293/STF cells were transfected with each of the 10 mouse Frizzleds either with or without Wnt9b. An increase in luciferase activity attributable to Wnt9b/Frizzled synergy is seen only with Fz5 and, to a lesser extent, with Fz8, the Frizzled family member with the highest degree of sequence similarity to Fz5 (Fig. 9B).

Unfortunately, our inability to produce soluble Wnt9b has precluded the simplest biochemical test of a direct and specific interaction between Wnt9b and Fz5. However, as an indirect test of the specificity of this hypothesized interaction, 293/STF cells were cotransfected with Fz5 and Wnt9b together with the $\mathrm{N}$-terminal ligand-binding domain [also referred to as the cysteine-rich domain (CRD)] from each of the 10 Frizzleds in the form of myc-epitope-tagged GPI-anchored derivatives. Previous work demonstrated efficient plasma membrane localization of these Frizzled CRD-myc-GPI derivatives and their accessibility to extracellular ligands, including Wnts and antibodies (Hsieh et al., 1999; Xu et al., 2004; Smallwood et al., 2007). In the cotransfection experiment shown in Figure $9 C$, the Fz5 and Fz8 CRDs efficiently inhibited signaling by coexpressed Wnt9b and Fz5, whereas the remaining eight Frizzled CRDs had little or no effect. To further examine the specificity of this inhibition, we measured the extent of this inhibition in the context of different inducers of
B

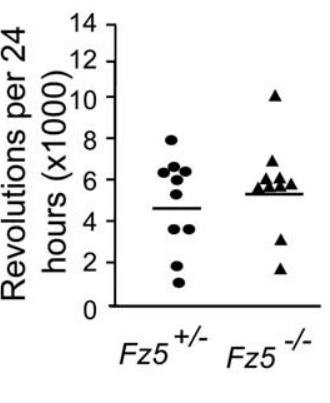

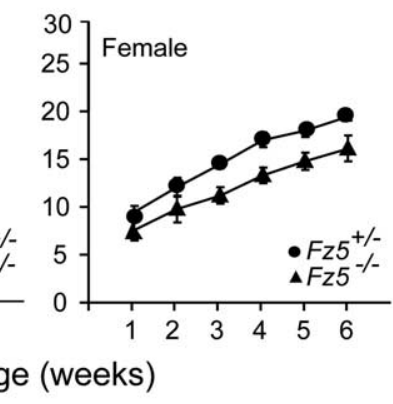

1 revolution per 6 seconds
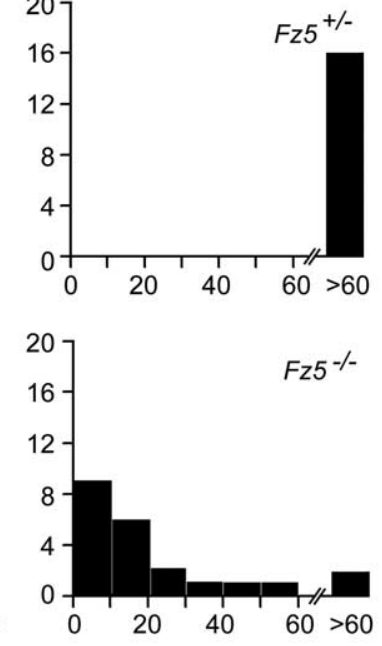

1 revolution per 3 seconds
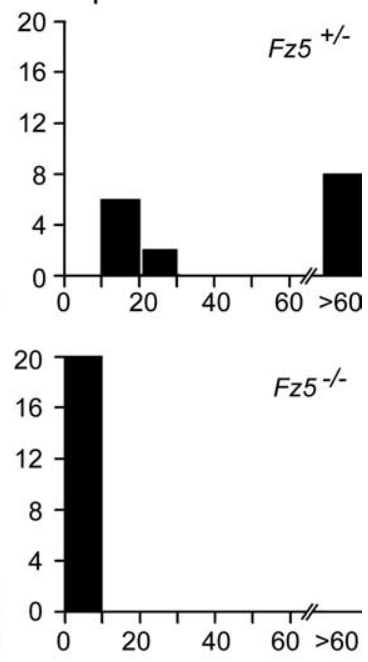

Average time before falling off (seconds)

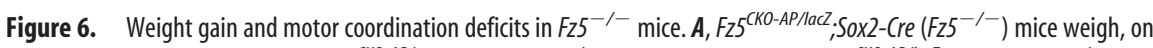

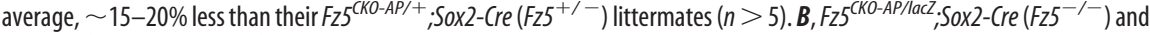
$\mathrm{F}_{75} \mathrm{CKO}^{\mathrm{AP} / \mathrm{AaC}}$;SOX2-Cre $\left(\mathrm{Fz}^{-1-}\right)$ mice have impaired performance in a rotorod test. Results are shown for three different rotation speeds. Each mouse was tested three times for each rotation speed. The average time to falling from the rotorod is shown.

canonical Wnt signaling (Fig. 9D). Overexpression of $\beta$-catenin or a constitutively active Lrp6 hybrid receptor (EpoR-Lrp6, in which the extracellular domain of Lrp6 has been replaced by the extracellular domain of the erythropoietin receptor) activates canonical signaling in a manner that should be mostly or completely independent of Wnt ligands and Frizzled receptors, and both show only modest inhibition (approximately twofold or less) by Fz5 CRD-myc-GPI. Wnt1, which strongly activates signaling in 293/STF cells, presumably by binding to one or more endogenous Frizzled receptors, is inhibited more than 10 -fold by Fz5 CRD-myc-GPI. Signaling by Lrp5, Fz4, and Norrin, a nonWnt ligand specific for Fz4 (Xu et al., 2004; Smallwood et al., 2007 ) exhibits $\sim 15 \%$ inhibition by Fz5 CRD-myc-GPI and $\sim 50 \%$ inhibition by Fz4 CRD-myc-GPI, whereas signaling by Wnt9b and Fz5 is inhibited $>10$-fold by Fz5 CRD-myc-GPI and not at all by Fz4 CRD-myc-GPI.

The simplest interpretation of these cell culture experiments is that Wnt9b can bind to Fz5 to activate canonical signaling, that Wnt9b can activate Fz5 and Fz8 more effectively than other Frizzleds, and that coexpressed Fz5 or Fz8 CRDs can inhibit Wnt9b- 
A

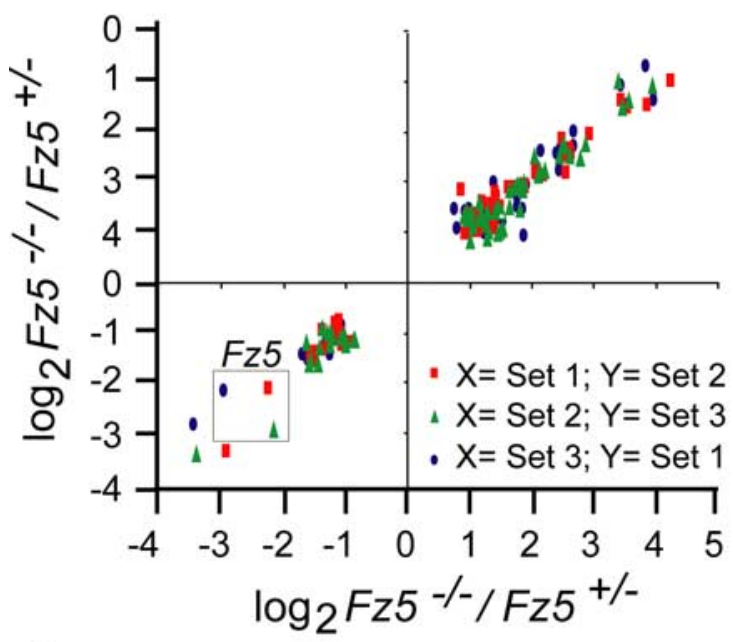

B

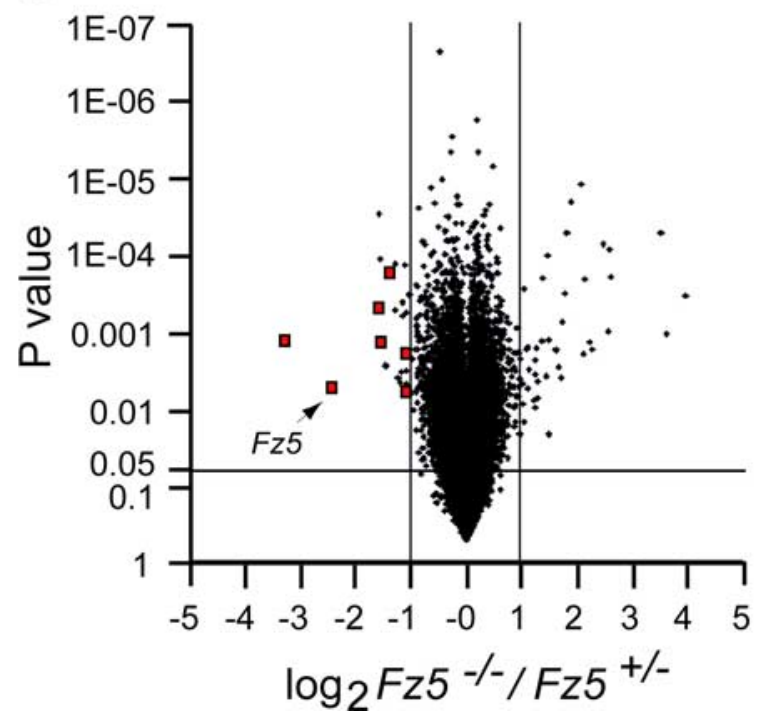

C

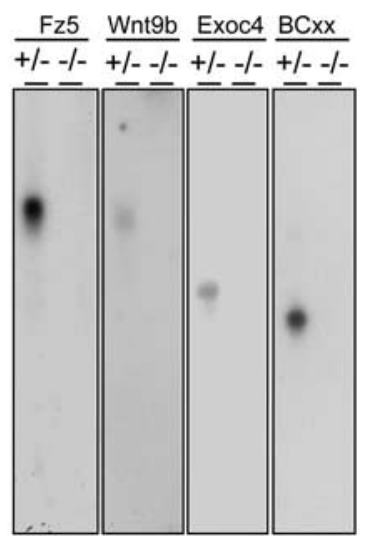

ST6 Lypd6 Pmch Rara

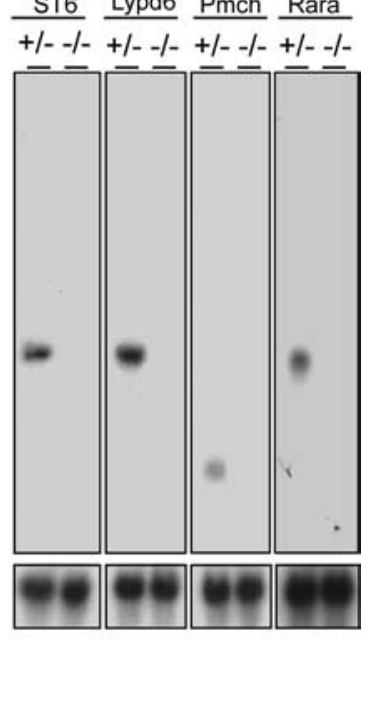

Figure 7. Microarray hybridization of adult $\mathrm{F}_{7} 5^{+/-}$versus $\mathrm{F}_{7} 5^{-/-}$PFN. A, PFN RNA was prepared from three independent

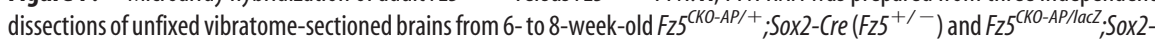
$\mathrm{Cre}\left(\mathrm{F}_{75} 5^{-/-}\right)$mice. For each RNA sample, tissue was pooled from three or more brains and hybridized to Affymetrix 4302.0 chips, representing 39,000 mouse transcripts. The figure shows pairwise comparisons among the three independent experiments for those transcripts that showed a more than twofold change in $\mathrm{F}_{75^{-1-}}: \mathrm{F}_{7} 5^{+/-}$abundance ratios. For genes with more than one entry in the Affymetrix spreadsheet, the scatter plot shows only the entry with the greatest change in transcript abundance. $\boldsymbol{B}$, The data from the three independent microarray hybridization experiments are shown as a scatter plot with the average $\mathrm{F}_{7} 5^{-1-}$ : $\mathrm{F}_{75^{+/-}}$transcript abundance ratio on the horizontal axis and the $p$ value for each ratio on the vertical axis. For genes with more than one entry in the Affymetrix spreadsheet and transcripts abundance changes of greater than twofold, the scatter plot shows only the entry with the greatest change in transcript abundance. Red squares, Probes used for RNA blot hybridization in C. C, Blot hybridization to PFN RNA dissected from unfixed vibratome-sectioned age-matched adult brains. Probes are from transcripts that

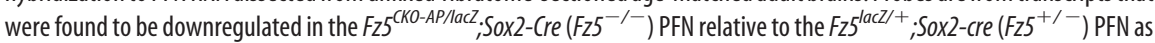
determined by in situ hybridization (Figs. 3,4) or microarray hybridization. Top, The same four blots that were used in the bottom images, stripped and reprobed. Bottom, The GAPDH transcript serves as a control. The abbreviated probe names and National Center for Biotechnology Information accession numbers are as follows: $B C X x$, a gene of unknown function (BC126943); Exoc4, exocyst component 4 (BC034644); Lypd6, LY6/PLAUR domain protein (BC070462); Pmch, premelanin concentrating hormone (BC048543); Rara, retinoic acid receptor $\alpha$ (BC010216); ST6, $(\alpha-N$-acetyl-neuraminyl-2,3- $\beta$-galactosyl-1,3)- $N$ acetylgalactosaminide $\alpha$-2,6-sialyltransferase (BC058387).

Fz5 signaling by competitively interfering with productive Wnt9b-Fz5 complexes.

\section{Discussion}

The principal results of this study are that (1) in the thalamus, Fz5 is specifically expressed in the PFN; (2) the absence of Fz5 leads to early postnatal changes in gene expression within the PFN and the subsequent loss of mature PFN neurons, which is associated with defects in motor coordination; (3) Fz5 is required continuously and in a cell autonomous manner for the survival of adult PFN neurons; and (4) Wnt9b is a likely Fz5 ligand in vivo and, together with $\beta$-catenin, is downregulated in the $\mathrm{Fz}^{-/-}$ $\mathrm{PFN}$, implying the existence of a positive feedback loop in which signaling via Fz5 is required to maintain the expression of genes that code for Wnt signaling components. The data presented here provide compelling evidence that ongoing canonical Wnt-Frizzled signaling is required for the survival of at least some adult CNS neurons. These observations suggest the general possibility that neuronal loss in some degenerative CNS diseases could arise from derangements in Wnt-Frizzled signaling.

\section{Wnt-Fz5 signaling in the thalamus}

As noted in the Introduction, most studies of Wnt and Frizzled signaling in the CNS have focused on developmental effects. Within the thalamus, two major effects have been reported. First, canonical Wnt signaling is required for the proliferation of precursors of all of the dorsal thalamic nuclei, because loss of the Frizzled coreceptor Lrp6 leads to a nearly complete absence of these structures (Zhou et al., 2004). Second, pathfinding by thalamocortical axons requires the functions of Fz3 and Celsr3, which likely act in a manner analogous to that of their Drosophila homologues in the context of planar cell polarity (Wang et al., 2002, 2006; Tissir et al., 2005).

The ability of Wnt9b, Lrp6, and Fz5 to activate canonical Wnt signaling in a reporter cell line, their coexpression in the PFN, and the absence of any tissue polarity aspect to the Fz5 phenotype, suggests that these three proteins interact in vivo to promote canonical but not planar cell polarity signaling. Consistent with this inference and with the direct effects of canonical Wnt signaling on gene transcription, the absence of Fz5 leads to numerous changes in transcript abundance in the PFN that precede cell-autonomous neuronal death. Whether Fz5 also acts in the context of Wnt-calcium signaling, a third pathway for Frizzled signaling (Kohn and Moon, 2005), is currently an open question. Whatever the mode(s) of Fz5 signal transduction in vivo, it is striking that Fz5 plays such a critical role in maintaining adult PFN neuron viability, whereas the loss of Fz5 has no apparent effect on proliferation, migration, or axonal growth and targeting of developing PFN neurons. If Fz5 functions during PFN devel- 


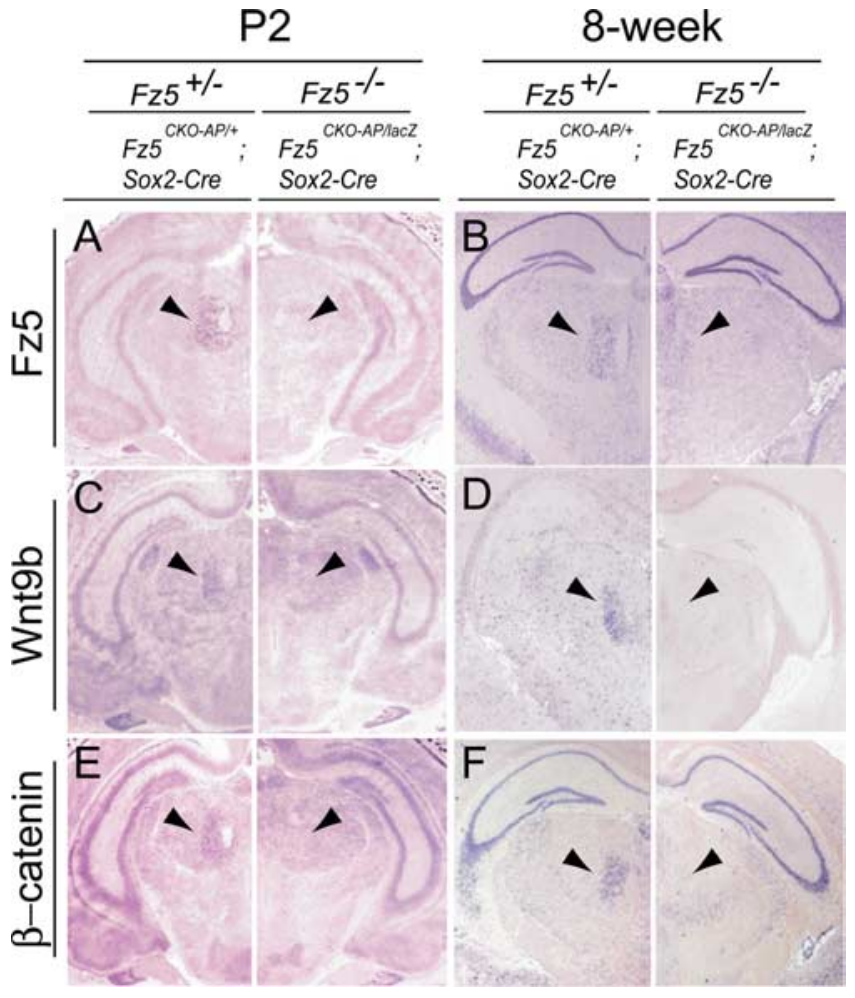

Figure 8. Downregulation of Wnt9b and $\beta$-catenin transcripts in the $\mathrm{F}_{2} 5^{-/-} \mathrm{PFN} . \mathbf{A - F}$, In situ hybridization to coronal sections through the PFN from P2 (left) and 8-week-old (right) $\mathrm{F}_{75} 5^{\mathrm{CKO}-\mathrm{AP} /+} ;$; $\mathrm{SOX2} 2-\mathrm{Cre}\left(\mathrm{FF}_{7} 5^{+/-}\right)$and $\mathrm{F}_{7} 5^{\mathrm{CKO}-\mathrm{AP} / \mathrm{IaCZ}}$;SOX2-Cre $\left(\mathrm{F}_{7} 5^{-/-}\right)$brains, using probes derived from $\mathrm{Fz} 5$, Wnt $9 \mathrm{~b}$, and $\beta$-catenin CDNAs. Each probe hybridizes to the PFN in the $\mathrm{F}_{25}{ }^{+/-}$, but not in the $\mathrm{F}_{75} 5^{--}$brain (arrowheads).

opment, its function may be mostly or completely redundant with one or more other Frizzleds.

\section{The function of the parafascicular nucleus}

Defining the distinctive functions of the various thalamic nuclei has been a longstanding goal of CNS neuroanatomists and neurophysiologists (Jones, 2007). As noted in the Introduction, a variety of functions have been ascribed to the PFN, including pain transmission, attention-dependent orientation, and odorant-based memory. The most extensively characterized of these functions relates to transmitting pain signals and to generating the affective component of pain. In humans, intraoperative stimulation of the centromedian nucleus/PFN complex leads to an unpleasant or painful sensation, positron emission tomography and functional magnetic resonance imaging studies have revealed activation of the medial thalamus (including the centromedian nucleus/PFN complex) in response to painful stimuli, and ablating the centromedian nucleus/PFN complex has been used, albeit with mixed success, in the treatment of chronic pain syndromes (Davis et al., 1998; Casey, 1999; Weigel and Krauss, 2004). In rats, stereotactic injection of morphine, carbachol, or 8-hydroxy-dipropylaminotetralin [8-OH-DPAT; a serotonin (5HT) $-1 \mathrm{~A}$ and $5 \mathrm{HT}-7$ receptor agonist] into the PFN leads to an elevated threshold for the vocalization response to acute tail pain, but has no effect on the tail-flick response (Carr and Bak, 1988; Harte et al., 2000, 2004, 2005). These observations indicate that the PFN participates in the forebrain response to pain but plays little or no role in spinal reflexes.

In the course of assessing the role of the rat PFN in the pain response, Harte et al. (2004, 2005) noted the frequent occurrence of complex motor responses to local drug infusion. Among these motor behaviors were rotating, head tilting, and climbing after local infusion of carbachol, and forepaw treading, hind limb hyperextension, intermittent muscle spasms, and spontaneous tail flicking after local infusion of 8-OH-DPAT. These observations imply a role for the PFN in complex motor behaviors and are consistent with the dense projections from the PFN to the sensorimotor territory of the striatum and globus pallidus (Yasukawa et al., 2004). In the present study the poor rotorod performance of $\mathrm{Fz}^{-/-}$mice strongly supports a role for the PFN in sensorimotor function.

\section{Implications for genetically directed ablation of neurons within identified brain nuclei}

For over a century, functional neuroanatomists have probed the role of different brain structures by selectively severing axon tracts or ablating cortical areas and subcortical nuclei (Jung and Hassler, 1960). Until relatively recently, these experiments were performed with classical neurosurgical methods, with the attendant problems of bleeding or scarring at the target site or in structures overlying deeper targets, as well as the requirement that each procedure be performed twice to obtain bilateral ablation. Over the past several decades, refinements in this approach have included (1) chemical ablation by local application of excitotoxic compounds such as ibotenic acid (Newsome and Pare, 1988); (2) chemical ablation by systemic or local application of compounds that are selectively toxic for subsets of neurons based on neurotransmitter type or other biochemical characteristics, such as 1-methyl-4-phenyl-1,2,3,6-tetrahydropyridine, 6-hydroxydopamine, p-chloramphetamine, or the immunotoxin 192-IgG saporin (Mamounas et al., 1991; Heckers et al., 1994; Langston, 1996; Deumens et al., 2002;); (3) localized electrolytic ablation guided by microelectrode mapping of single-unit responses (Kirschman et al., 2000); and (4) local and nontoxic pharmacologic blockade of one or more subsets of neurotransmitter systems (Harte et al., 2000). Although these techniques have led to greater control over the size, location, and neurotransmitter characteristics of the targets of ablation or inactivation, the challenge of efficiently and selectively ablating or inactivating large and irregularly shaped groups of neurons remains formidable.

The development of technologies for genetic manipulation in the mouse has created a new set of noninvasive or minimally invasive approaches for selective ablation or inactivation of neurons. Thus far, the utility of these approaches has been limited by the availability of characterized promoters or genes that are, respectively, expressed in or required for the development of single anatomically or functionally defined CNS structures. For example, in the thalamus, transcription factor genes are typically expressed in overlapping patterns, with the expression domain of each gene generally encompassing multiple thalamic nuclei (Nakagawa and O'Leary, 2001; Jones and Rubenstein, 2004). However, improved regional and/or cell-type specificity, as well as temporal control, should be possible either by the combinatorial manipulation of gene expression with the CreER/4HT or reverse Tet transactivator (rtTA)/tetracycline systems (Feil et al., 1996; Backman et al., 2004), or by pharmacologically or optically activating or inactivating genetically targeted neurons (Lechner et al., 2002, 2007; Zhang et al., 2007).

The observations described in this study are encouraging for the development of genetic approaches to CNS region-specific or nucleus-specific ablation or inactivation. In particular, the restricted expression of $F z 5$ suggests that naturally occurring or 
A

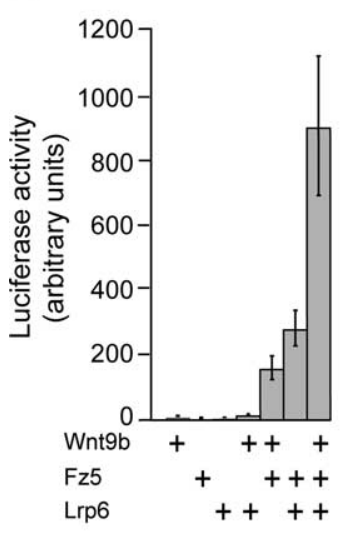

B

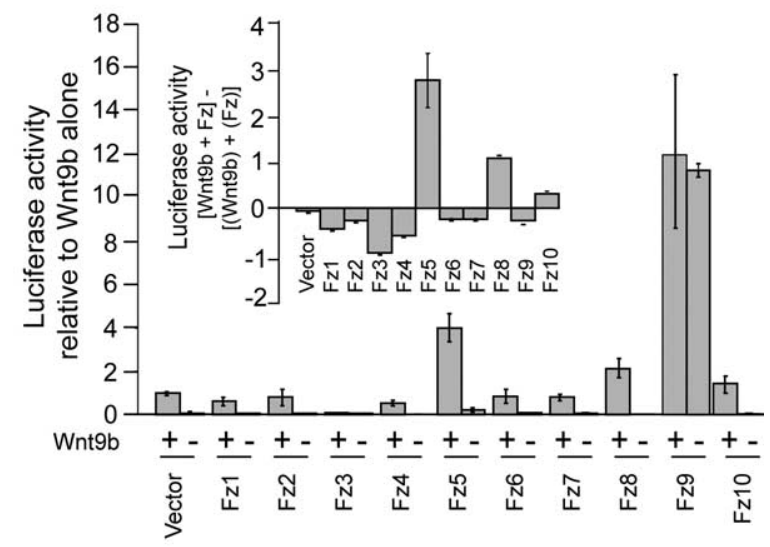

C

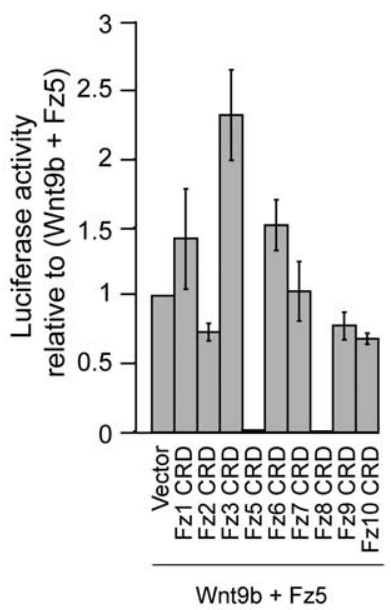

D

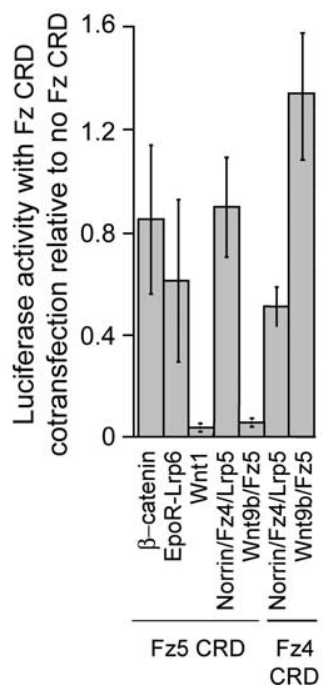

Figure 9. Evidence that Wnt $9 \mathrm{~b}$ and Fz5 can synergistically activate the canonical Wnt signaling pathway. A, Luciferase activity caused by canonical Wnt signaling after transient cotransfection of the $293 /$ STF luciferase reporter cell line with the indicated plasmids. B, Relative specificity of Wnt9b for Fz5 compared with other Frizzleds in cotransfected 293/STF cells. Note that Fz9 has strong constitutive activity in the absence of Wnt9b. Inset, The excess luciferase activity attributable to Wnt9b-Fz interactions calculated by subtracting the sum of the luciferase activity of cells individually transfected with Wnt $9 \mathrm{~b}$ and with the indicated Frizzled from the luciferase activity of cells cotransfected with Wnt $9 \mathrm{~b}$ and the same Frizzled. C, Inhibition of Wnt9b-Fz5 signaling in 293/STF cells by coexpression of plasma-membrane localized, myc-tagged, and GPI-anchored fusion proteins with the CRD from each of the 10 mouse Frizzleds. The Fz5 and Fz8 CRDs produce nearly complete inhibition of canonical Wnt signaling; the remaining eight Frizzled CRDs produce little or no inhibition. D, Specificity of inhibition of Frizzled signaling by Fz5 CRD myc-GPI. The histogram shows the ratio of 293/STF luciferase activity in the presence of Fz5 CRD-myc-GPI or Fz4 CRD-myc-GPI relative to the 293/STF luciferase activity in the absence of a CRD-myc-GPI inhibitor. All histograms show the mean \pm SD of triplicate transfections.

artificial combinations of promoter elements can be identified that confer a high degree of anatomic specificity. Finally, we note that the continuous and cell-autonomous requirement for $\mathrm{Fz} 5 \mathrm{in}$ maintaining the viability of mature but not developing PFN neurons suggests that manipulating Frizzled signaling could provide another method for selectively ablating neurons in the mature brain.

\section{References}

Aymerich MS, Barroso-Chinea P, Perez-Manso M, Munoz-Patino AM, Moreno-Igoa M, Gonzalez-Hernandez T, Lanciego JL (2006) Consequences of unilateral nigro-striatal denervation on the thalamostriatal pathway in rats. Eur J Neurosci 23:2099-2108.

Backman CM, Zhang Y, Hoffer BJ, Tomac AC (2004) Tetracycline-

inducible expression systems for the generation of transgenic animals: a comparison of various inducible systems carried in a single vector. J Neurosci Methods 139:257-262.

Badea TC, Wang Y, Nathans J (2003) A noninvasive genetic/pharmacologic strategy for visualizing cell morphology and clonal relationships in the mouse. J Neurosci 23:2314-2322.

Carmichael J, Sugars KL, Bao YP, Rubinsztein DC (2002) Glycogen synthase kinase-3 $\beta$ inhibitors prevent cellular polyglutamine toxicity caused by the Huntington's disease mutation. J Biol Chem 277:33791-33798.

Carr KD, Bak TH (1988) Medial thalamic injection of opioid agonists: mu-agonist increases while kappa-agonist decreases stimulus thresholds for pain and reward. Brain Res 441:173-184.

Casey KL (1999) Forebrain mechanisms of nociception and pain: analysis through imaging. Proc Natl Acad Sci USA 96:7668-7674.

Chen J, Rattner A, Nathans J (2005) The rod photoreceptor-specific nuclear receptor $\mathrm{Nr} 2 \mathrm{e} 3$ represses transcription of multiple conespecific genes. J Neurosci 25:118-129.

Crawley JN (2000) What's wrong with my mouse? Behavioral phenotyping of transgenic and knockout mice, p 329. New York: Wiley.

Davis KD, Kwan CL, Crawley AP, Mikulis DJ (1998) Functional MRI study of thalamic and cortical activations evoked by cutaneous heat, cold, and tactile stimuli. J Neurophysiol 80:1533-1546.

De Ferrari GV, Moon RT (2006) The ups and downs of Wnt signaling in prevalent neurological disorders. Oncogene 25:7545-7553.

De Ferrari GV, Papassotiropoulos A, Biechele T, Wavrant De-Vrieze F, Avila ME, Major MB, Myers A, Saez K, Henriquez JP, Zhao A, Wollmer MA, Nitsch RM, Hock C, Morris CM, Hardy J, Moon RT (2007) Common genetic variation within the low-density lipoprotein receptorrelated protein 6 and late-onset Alzheimer's disease. Proc Natl Acad Sci USA 104:9434-9439.

Deschenes M, Bourassa J, Doan VD, Parent A (1996) A single-cell study of the axonal projections arising from the posterior intralaminar thalamic nuclei in the rat. Eur J Neurosci 8:329-343.

Deumens R, Blokland A, Prickaerts J (2002) Modeling Parkinson's disease in rats: an evaluation of 6-OHDA lesions of the nigrostriatal pathway. Exp Neurol 175:303-317.

Feil R, Brocard J, Mascrez B, LeMeur M, Metzger D, Chambon P (1996) Ligand-activated sitespecific recombination in mice. Proc Natl Acad Sci USA 93:10887-10890.

Franklin KB, Paxinos G (1997) The mouse brain in stereotaxic coordinates. New York: Academic.

Galceran J, Miyashita-Lin EM, Devaney E, Rubenstein JL, Grosschedl R (2000) Hippocampus development and generation of dentate gyrus granule cells is regulated by LEF1. Development 127:469-482.

Gomez-Sintes R, Hernandez F, Bortolozzi A, Artigas F, Avila J, Zaratin P, Gotteland JP, Lucas JJ (2007) Neuronal apoptosis and reversible motor deficit in dominant-negative GSK-3 conditional transgenic mice. EMBO J 26:2743-2754.

Hall AC, Lucas FR, Salinas PC (2000) Axonal remodeling and synaptic differentiation in the cerebellum is regulated by WNT-7a signaling. Cell 100:525-535.

Harte SE, Lagman AL, Borszcz GS (2000) Antinociceptive effects of morphine injected into the nucleus parafascicularis thalami of the rat. Brain Res 874:78-86. 
Harte SE, Hoot MR, Borszcz GS (2004) Involvement of the intralaminar parafascicular nucleus in muscarinic-induced antinociception in rats. Brain Res 1019:152-161.

Harte SE, Kender RG, Borszcz GS (2005) Activation of 5-HT1A and 5-HT7 receptors in the parafascicular nucleus suppresses the affective reaction of rats to noxious stimulation. Pain 113:405-415.

Hayashi S, Lewis P, Pevny L, McMahon AP (2002) Efficient gene modulation in mouse epiblast using a Sox2Cre transgenic mouse strain. Gene Expr Patterns 2:93-97.

Hayashi S, Tenzen T, McMahon AP (2003) Maternal inheritance of Cre activity in a Sox2Cre deleter strain. Genesis 37:51-53.

Heckers S, Ohtake T, Wiley RG, Lappi DA, Geula C, Mesulam MM (1994) Complete and selective cholinergic denervation of rat neocortex and hippocampus but not amygdala by an immunotoxin against the p75 NGF receptor. J Neurosci 14:1271-1289.

Henderson JM, Carpenter K, Cartwright H, Halliday GM (2000) Degeneration of the centre median-parafascicular complex in Parkinson's disease. Ann Neurol 47:345-352.

Hsieh JC, Rattner A, Smallwood PM, Nathans J (1999) Biochemical characterization of Wnt-Frizzled interactions using a soluble, biologically active vertebrate Wnt protein. Proc Natl Acad Sci USA 96:3546-3551.

Ishikawa T, Tamai Y, Zorn AM, Yoshida H, Seldin MF, Nishikawa S, Taketo MM (2001) Mouse Wnt receptor gene Fzd5 is essential for yolk sac and placental angiogenesis. Development 128:25-33.

Jones EG (2007) The thalamus, Ed 2, p 1708. Cambridge, UK: Cambridge UP.

Jones EG, Rubenstein JL (2004) Expression of regulatory genes during differentiation of thalamic nuclei in mouse and monkey. J Comp Neurol 477:55-80.

Jung R, Hassler R (1960) The extrapyramidal motor system. In: Handbook of physiology. Section 1: Neurophysiology, Vol II (Field J, Magoun HW, Hall VE, eds), pp 863-927. Washington, D.C.: American Physiological Society.

Kaelber WW, Mitchell CL, Yarmat AJ, Afifi AK, Lorens SA (1975) Centrummedianum-parafascicularis lesions and reactivity to noxious and nonnoxious stimuli. Exp Neurol 46:282-290.

Kirschman DL, Milligan B, Wilkinson S, Overman J, Wetzel L, Batnitzky S, Lyons K, Pahwah R, Koller WC, Gordon MA (2000) Pallidotomy microelectrode targeting: neurophysiology-based target refinement. Neurosurgery 46:613-622.

Kobayashi S, Nakamura Y (2003) Synaptic organization of the rat parafascicular nucleus, with special reference to its afferents from the superior colliculus and the pedunculopontine tegmental nucleus. Brain Res 980:80-91.

Kohn AD, Moon RT (2005) Wnt and calcium signaling: beta-cateninindependent pathways. Cell Calcium 38:439-446.

Lacey CJ, Bolam JP, Magill PJ (2007) Novel and distinct operational principles of intralaminar thalamic neurons and their striatal projections. J Neurosci 27:4374-4384.

Langston JW (1996) The etiology of Parkinson's disease with emphasis on the MPTP story. Neurology 47:S153-S160.

Lechner HA, Lein ES, Callaway EM (2002) A genetic method for selective and quickly reversible silencing of Mammalian neurons. J Neurosci 22:5287-5290.

Lee JM, Zipfel GJ, Choi DW (1999) The changing landscape of ischaemic brain injury mechanisms. Nature 39:A7-A14.

Lee SM, Tole S, Grove E, McMahon AP (2000) A local Wnt-3a signal is required for development of the mammalian hippocampus. Development 127:457-467.

Lein ES, Hawrylycz MJ, Ao N, Ayres M, Bensinger A, Bernard A, Boe AF, Boguski MS, Brockway KS, Byrnes EJ, Chen L, Chen L, Chen TM, Chin MC, Chong J, Crook BE, Czaplinska A, Dang CN, Datta S, Dee NR (2007) Genome-wide atlas of gene expression in the adult mouse brain. Nature 445:168-176.

Lerchner W, Xiao C, Nashmi R, Slimko EM, van Trigt L, Lester HA, Anderson DJ (2007) Reversible silencing of neuronal excitability in behaving mice by a genetically targeted, ivermectin-gated $\mathrm{Cl}^{-}$channel. Neuron 54:35-49.

Lobe CG, Koop KE, Kreppner W, Lomeli H, Gertsenstein M, Nagy A (1999) Z/AP, a double reporter for cre-mediated recombination. Dev Biol 208:281-292.

Lucas JJ, Hernandez F, Gomez-Ramos P, Moran MA, Hen R, Avila J (2001)
Decreased nuclear beta-catenin, tau hyperphosphorylation and neurodegeneration in GSK-3beta conditional transgenic mice. EMBO J 20:27-39.

Lyuksyutova AI, Lu CC, Milanesio N, King LA, Guo N, Wang Y, Nathans J, Tessier-Lavigne M, Zou Y (2003) Anterior-posterior guidance of commissural axons by Wnt-frizzled signaling. Science 302:1984-1988.

Mamounas LA, Mullen CA, O'Hearn E, Molliver ME (1991) Dual serotoninergic projections to forebrain in the rat: morphologically distinct 5-HT axon terminals exhibit differential vulnerability to neurotoxic amphetamine derivatives. J Comp Neurol 314:558-586.

Matsumoto N, Minamimoto T, Graybiel AM, Kimura M (2001) Neurons in the thalamic CM-Pf complex supply striatal neurons with information about behaviorally significant sensory events. J Neurophysiol 85:960-976.

McBride JL, Ramaswamy S, Gasmi M, Bartus RT, Herzog CD, Brandon EP, Zhou L, Pitzer MR, Berry-Kravis EM, Kordower JH (2006) Viral delivery of glial cell line-derived neurotrophic factor improves behavior and protects striatal neurons in a mouse model of Huntington's disease. Proc Natl Acad Sci USA 103:9345-9350.

Megason SG, McMahon AP (2002) A mitogen gradient of dorsal midline Wnts organizes growth in the CNS. Development 129:2087-2098.

Minamimoto T, Kimura M (2002) Participation of the thalamic CM-Pf complex in attentional orienting. J Neurophysiol 87:3090-3101.

Muroyama Y, Fujihara M, Ikeya M, Kondoh H, Takada S (2002) Wnt signaling plays an essential role in neuronal specification of the dorsal spinal cord. Genes Dev 16:548-553.

Nakagawa Y, O’Leary DD (2001) Combinatorial expression patterns of LIM-homeodomain and other regulatory genes parcellate developing thalamus. J Neurosci 21:2711-2725.

Nakamura Y, Otake K, Tokuno H (2006) The parafascicular nucleus relays spinal inputs to the striatum: an electron microscope study in the rat. Neurosci Res 56:73-79.

Nash JE, Johnston TH, Collingridge GL, Garner CC, Brotchie JM (2005) Subcellular redistribution of the synapse-associated proteins PSD-95 and SAP97 in animal models of Parkinson's disease and L-DOPA-induced dyskinesia. FASEB J 19:583-585.

Newsome WT, Pare EB (1988) A selective impairment of motion perception following lesions of the middle temporal visual area (MT). J Neurosci 8:2201-2211.

Parent M, Parent A (2005) Single-axon tracing and three-dimensional reconstruction of centre median-parafascicular thalamic neurons in primates. J Comp Neurol 481:127-144.

Quiroz-Padilla MF, Guillazo-Blanch G, Vale-Martinez A, Torras-Garcia M, Marti-Nicolovius M (2007) Effects of parafascicular excitotoxic lesions on two-way active avoidance and odor-discrimination. Neurobiol Learn Mem 88:198-207.

Royce GJ, Mourey RJ (1985) Efferent connections of the centromedian and parafascicular thalamic nuclei: an autoradiographic investigation in the cat. J Comp Neurol 235:277-300.

Royce GJ, Bromley S, Gracco C (1991) Subcortical projections to the centromedian and parafascicular thalamic nuclei in the cat. J Comp Neurol 306:129-155.

Saade NE, Al Amin H, Abdel Baki S, Chalouhi S, Jabbur SJ, Atweh SF (2007) Reversible attenuation of neuropathic-like manifestations in rats by lesions or local blocks of the intralaminar or the medial thalamic nuclei. Exp Neurol 204:205-219.

Sadikot AF, Parent A, Francois C (1992a) Efferent connections of the centromedian and parafascicular thalamic nuclei in the squirrel monkey: a PHA-L study of subcortical projections. J Comp Neurol 315:137-159.

Sadikot AF, Parent A, Smith Y, Bolam JP (1992b) Efferent connections of the centromedian and parafascicular thalamic nuclei in the squirrel monkey: a light and electron microscopic study of the thalamostriatal projection in relation to striatal heterogeneity. J Comp Neurol 320:228 -242.

Schaeren-Wiemers N, Gerfin-Moser A (1993) A single protocol to detect transcripts of various types and expression levels in neural tissue and cultured cells: in situ hybridization using digoxygenin-labelled cRNA probes. Histochemistry 100:431-440.

Shimogori T, VanSant J, Paik E, Grove EA (2004) Members of the Wnt, Fz, and Frp gene families expressed in postnatal mouse cerebral cortex. J Comp Neurol 473:496-510.

Shiroyama T, Kayahara T, Yasui Y, Nomura J, Nakano K (1995) The vestibular nuclei of the rat project to the lateral part of the thalamic parafascicular nucleus (centromedian nucleus in primates). Brain Res 704:130-134. 
Smallwood PM, Williams J, Xu Q, Leahy DJ, Nathans J (2007) Mutational analysis of Norrin-Frizzled4 recognition. J Biol Chem 282:4057-4068.

Smeal RM, Gaspar RC, Keefe KA, Wilcox KS (2007) A rat brain slice preparation for characterizing both thalamostriatal and corticostriatal afferents. J Neurosci Methods 159:224-235.

Tissir F, Bar I, Jossin Y, De Backer O, Goffinet AM (2005) Protocadherin Celsr3 is crucial in axonal tract development. Nat Neurosci 8:451-457.

Vercelli A, Marini G, Tredici G (2003) Anatomical organization of the telencephalic connections of the parafascicular nucleus in adult and developing rats. Eur J Neurosci 18:275-289.

Wang Y, Macke JP, Abella BS, Andreasson K, Worley P, Gilbert DJ, Copeland NG, Jenkins NA, Nathans J (1996) A large family of putative transmembrane receptors homologous to the product of the Drosophila tissue polarity gene frizzled. J Biol Chem 271:4468-4476.

Wang Y, Huso D, Cahill H, Ryugo D, Nathans J (2001) Progressive cerebellar, auditory, and esophageal dysfunction caused by targeted disruption of the frizzled-4 gene. J Neurosci 21:4761-4771.

Wang Y, Thekdi N, Smallwood PM, Macke JP, Nathans J (2002) Frizzled-3 is required for the development of major fiber tracts in the rostral CNS. J Neurosci 22:8563-8573.

Wang Y, Zhang J, Mori S, Nathans J (2006) Axonal growth and guidance defects in Frizzled3 knock-out mice: a comparison of diffusion tensor magnetic resonance imaging, neurofilament staining, and genetically directed cell labeling. J Neurosci 26:355-364.

Weigel R, Krauss JK (2004) Center median-parafascicular complex and pain control. Rev from a neurosurgical perspective. Stereotact Funct Neurosurg 82:115-126.

Xu Q, Wang Y, Dabdoub A, Smallwood PM, Williams J, Woods C, Kelley MW, Jiang L, Tasman W, Zhang K, Nathans J (2004) Vascular development in the retina and inner ear: control by Norrin and Frizzled-4, a high-affinity ligand-receptor pair. Cell 116:883-895.

Xuereb JH, Perry RH, Candy JM, Perry EK, Marshall E, Bonham JR (1991) Nerve cell loss in the thalamus in Alzheimer's disease and Parkinson's disease. Brain 114:1363-1379.

Yasukawa T, Kita T, Xue Y, Kita H (2004) Rat intralaminar thalamic nuclei projections to the globus pallidus: a biotinylated dextran amine anterograde tracing study. J Comp Neurol 471:153-167.

Yu X, Malenka RC (2003) Beta-catenin is critical for dendritic morphogenesis. Nat Neurosci 6:1169-1177.

Zhang F, Wang LP, Brauner M, Liewald JF, Kay K, Watzke N, Wood PG, Bamberg E, Nagel G, Gottschalk A, Deisseroth K (2007) Multimodal fast optical interrogation of neural circuitry. Nature 446:633-639.

Zhou CJ, Pinson KI, Pleasure SJ (2004) Severe defects in dorsal thalamic development in low-density lipoprotein receptor-related protein-6 mutants. J Neurosci 24:7632-7639. 